\title{
The Performance of Low Pressure Tissue Equivalent Chambers and a New Method for Parameterizing the Dose Equivalent
}

\author{
Y. Eisen* \\ D. G. Vasilik \\ R. J. Brake \\ B. H. Erkkila \\ G. J. Littlejohn
}




\title{
THE PERFORMANCE OF LOW PRESSURE TISSUE EQUIVALENT CHAMBERS AND A NEW \\ METHOD FOR PARAMETERIZING THE DOSE EQUIVALENT
}

\author{
$\because$ Eisen, D. G. Vasilik, R. J. Brake, B. H. Erkkila, \\ and G.J. Littlejohn
}

\section{ABSTRACT}

The performance of spherical tissue equivalent chambers with equivalent cilameters between 0.5 and $2 \mu$ was tested experimentally using monoenergetic and polyenergetic neutron sources in the energy region of $10 \mathrm{keV}$ to $14.5 \mathrm{M} \curvearrowright \mathrm{V}$. Theoretical calculations were performed in order to obtain a simple algorithm for deriving the dose equivalent from the measured data. The algorithm relates the number of recoil particles to the dose equivalent, rather than having a one-to-one correspondense between the lineal energy and the linear energy transfer of the recoil paiticles. The calculations took into account neutron interactions with hydrogen atoms in the chamber wall as well as in the gas, and also the finite energy resolution determined by both the detector and the electronic system. Qualitatively, the calculations well describe the experimental results. The algorithm that was developed determines the neutron dose equivalent, from the data of the $0.5 \mu$ chamber, to better than $\pm 20 \%$ over the energy range of $30 \mathrm{keV}$ to $14.5 \mathrm{MeV}$. The same algorithm also determines the dose equivalent from the data of the $2 \mu$ chamber to better than $\pm 20 \%$ over the energy of $70 \mathrm{keV}$ to $14.5 \mathrm{MeV}$.

The efficiency of the chambers is low and has an average value of 330 counts per mrem, or equivalently about $0.2 \mathrm{c} / \mathrm{s}$ per mrem $/ \mathrm{h}$. This efficiency enables the measurement of dose equivalent rates only above 100 mrem $/ \mathrm{h}$ for an integration period of 3 seconds. However, integrated dose equivalents can be measured as low as 0.1 mrem. 


\section{INTRODUCTION}

During the last few years there has been a growing interest in the development of small portable neutron dosimeters. (1-5) Real time dosimeters which are based on moderation of the incident neutrons are cumbersome, heavy and usually over-respond in the energy region of $1-100 \mathrm{keV}$ and under-respond in the energy region above $9 \mathrm{MeV}$.

Tissue equivalent proportional chambers, usually of the Rossi spherical type, $(6)$ measure the energy deposited by recoil particles in an appropriate gas corresponding to small tissue volumes. They have been utilized in field measurements $(1,2,7,8,9)$ to determine dose equivalents. Equivalent tissue thicknesses of 1 and $2 \mu$ have been used. $(1,2,8)$ In these studies the dose equivalent was found by using a functional relationship between the event size or lineal energy (energy deposited divided by an effective diameter of the chamber) and the LET (Linear Energy Transfer) of the recoiling particles. This method was determined to be improper, (10) especially for low neutron energies. The main reason for this is thet most of the recoil particles generated by low energy neutron interactions, are either stopped in the gas, or lose a large fraction of their energy when traversing the chamber. This contradicts the basic assumption made by Rossi $(6,11)$ that the energy loss of the recoil particles is negligible compared with their energy upon entering the gas.

Ricourt et al, $(12)$ and stinchcomb and Borak (13) sugges'ced the use of an effective parameter, $Y^{\prime}$, instead of the conventional lineal energy parameter, $Y$. The relation between the two was given by:

$y^{\prime}=\frac{8}{9} Y$

where $Y^{\prime}$ was equated to the LET. Theoretical calculations were performed ${ }^{(13)}$ to verify this approach, but no experimental evidence was given for low neutron energies in the range of $10-300 \mathrm{keV}$. This energy region is especially important for determining the dose equivalent in nuclear power reactors. (14)

The differentiation method proposed ny Rossi(11) nas another disadvantage for use in portable instruments. This method requires good counting statistics. on the other hand, tissue equivalent chambers of low pressure and moderate size have relatively low sensitivity to neutrons. 
In the present study we developed a simple theoretical algorithm for calculating the dose equivalent from the measured event size distribution in low pressure tissue equivalent chambers with effective tissue diameters between 0.5 and $2 \mu$. Because the Rossi assumptions fail for low neutron energies and practical chanber size, the method used in tris study does not correlate in a one-to-one correspondence between the lineal energy distribution and the LET of the recoil particles but rather divides the event size spectrum into, two regions, and uses the total number of counts in these regions to extract the dose equivalent. This method does not suffer from statistical limitations beyond those that are determined by the detector efficiency.

The theoretical method developed, which took into account only neutron-hydrogen elastic interactions in the chamber wall and the gas, was tested experimentally using monoenergetic neutrons in the energy region of 10 kev to $14.5 \mathrm{MeV}$ produced in the ${ }^{7} \mathrm{Li}(\mathrm{p}, \mathrm{n})^{7} \mathrm{Be}, \mathrm{D}(\mathrm{d}, \mathrm{n})^{3} \mathrm{He}$ and $\mathrm{T}(\mathrm{d}, \mathrm{n})^{4} \mathrm{He}$ reactions, and several polyenergetic neutron sources. Polyenergetic sources included $252 \mathrm{Cf}$ ( $E_{\text {ave }}=2.4 \mathrm{MeV}$ ), ${ }^{252} \mathrm{Cf}$ moderated by a $30 \mathrm{~cm}$ diameter sphere of $\mathrm{D}_{2} \mathrm{O}\left(\mathrm{E}_{\text {ave }}=2.2\right.$ $\mathrm{MeV}),{ }^{238} \mathrm{Pu}-\mathrm{F}\left(\mathrm{E}_{\mathrm{ave}}=1.1 \mathrm{MeV}\right),{ }^{238}{ }_{\mathrm{Pu}-\mathrm{B}}\left(\mathrm{E}_{\mathrm{ave}}=2.5 \mathrm{MeV}\right)$, and $238_{\mathrm{Pu}-\mathrm{Be}}\left(\mathrm{E}_{\text {ave }} \times\right.$ $4.5 \mathrm{MeV})$, where $E_{\text {ave }}$ is the dose equivalent-weighted average energy.

Section II describes the calculations performed to obtain the algorithm. In Section III the experimental studies are presented. The theoretical and experimental results are described in Section IV. Conclusions and summary are given in section $V$.

\section{THEORETICAL CONSIDERATIONS}

The theoretical calculations in this study were carried out in the energy region of $10 \mathrm{keV}$ to $14.5 \mathrm{Mev}$. The purpose of the calculations was to provide an algorithm for calculating the dose equivalent from the measured energy deposition of the recoil particles. In this energy region, the dose equivalent in tissue, contributed by charged particle recoils, originates mainly from elastic collisions of the incident neutrons with hydrogen atoms. Moreover, the number of events in the chamber is dominated by proton recoils. Therefore, the calculations performed considered only elastic scattering of the neutrons with hydrogen atoms in the wall and in the gas. A non-negligible fraction of the dose equivalent for neutron energies in the range of $10-50 \mathrm{keV}$ results from gamma interactions that are produced by neutron capture collisions. In order to 
measure this gamma contribution, the detector should be embedded inside a phantom. Our dosimeter measures the dose equivalent in free air and discriminates all gamma interactions in the detector. However the neutron fluence-to-dose equivalent convession factors utilized in the present study include the contribution of gamma interactions in the body, therefore compensating for the discrimination of the gammas. The calculations were not aimed to be complete and most accurate, and simplifying assumptions were made in order to fit them onto a Hewlett Packard $9845 \mathrm{~B}$ microcomputer. In spite of the simplifying assumptions, the calculations provide a guideline for a new algorithm which represents the dose equivalent.

The detectors considered were Rossi-type tissue equivalent chambers, with equivalent tissue diameters ranging between 0.5 and $2 \mu$. Both the walls, which are made of Shonka material, (15) and the tissue equivalent Fossi-type gas contain $10.3 \%$ hydrogen by mass (see Fig. 1).

It was assumed in the calculations that at each point in the wali the neutrons interact normal to the surface of the tissue equivalent chamber.

For neutron enërgies $\left(E_{n}\right)$ less than $0.5 \mathrm{MeV}$, the total cross section, $\sigma_{\text {tot' }}$ was parameterized in the following way: (16)

$$
\begin{aligned}
\sigma_{\text {tot }}(\text { barns }) & =3 \pi /\left[1.206 E_{n}+\left(-1.86+0.0842 E_{n}+0.00013 E_{n}^{2}\right)^{2}\right]+ \\
& \pi /\left[1.206 E_{n}+\left(0.422+0.13 E_{n}\right)^{2}\right]
\end{aligned}
$$

For neutron energies greater than or equal to $0.5 \mathrm{MeV}$, the total cross section was parameterized as follows: (17)

$$
\sigma_{\text {tot }}(\text { barns })=4.83 / \sqrt{E_{n}}-0.578
$$

where in both equations (2) and (3) the neutron energy is given in MeV.

The differential cross section was assumed to be isotropic in the center-of-mass system, leading to the following relation in the laboratory system:

$\frac{\mathrm{d} \sigma}{\mathrm{d} \Omega}\left(E_{n}\right)=\frac{\sigma_{\text {tot }}\left(E_{n}\right)}{\pi} \cdot \cos \theta$ 
where $\Theta$ is the proton scattering angle. The following assumptions were also made:

a. Multiple scattering of recoil protons was neglected even when the track length was of the order of the proton range, i.e. the protons were assumed to move in straight lines in the wall and in the gas.

b Neutrons interact only once with the wall material or the gas, i.e. no multiple neutron interactions were. considered.

c. The path lengths of the recoil protons and the energies deposited in the gas were found using the continuous-slowing-down approximation, i.e. the range $R$ for a given energy $E_{O}$ was determined by:

$R_{p}\left(E_{0}\right)=o^{E^{O}} d E /(d E / d x)$

where $\mathrm{dE} / \mathrm{dx}$ is the stopping power of the proton.

Under these assumptions, the number of recoil protons per unit area generated in the wall per incident neutron $/ \mathrm{cm}^{2}, \mathrm{~N}_{\mathrm{p}}\left(\mathrm{E}_{\mathrm{n}}\right)$, is given by:

$N_{p}\left(E_{n}\right)=6.2 \times 10^{-5} \int_{0}^{R_{\max }\left(E_{n}\right)} \int_{\phi=0}^{2 \pi} \int_{\theta=0}^{\Theta_{\max }(t)} \exp \left[-6.2 \times 10^{-5} \sigma_{\text {tot }}\left(E_{n}\right)(T-t)\right] \frac{d \sigma}{d \Omega}\left(E_{n}\right) d t d \Omega$

where $\Theta_{\max }\left(E_{n}\right)$ is the range of a proton with an energy $E_{n}$. The geometric notations of equation (6) are shown in Fig. 1. $\theta_{\max }\left(0 \leq \theta_{\max }(t) \leq \pi / 2\right)$ depends on the point of interaction, $t\left(\mathrm{mg} / \mathrm{cm}^{2}\right)$, in the wall and is the maximum proton scattering angle beyond which protons do not reach the gas; $T\left(\mathrm{mg} / \mathrm{cm}^{2}\right)$ is the thickness of the wall. It was also assumed that the area seen by the incident neutrons was nearly $R^{2}$, where $R$ is the radius of the sphere.

A similar equation to (6) was used to derive the number of interactions in the gas, $\mathrm{N}_{\mathrm{p}}{ }^{\prime}\left(\mathrm{E}_{\mathrm{n}}\right)$, and is given as follows:

$N_{p}^{\prime}\left(E_{n}\right)=6.2 \times 10^{-5} \exp \left[-6.2 \times 10^{-5} \sigma_{\text {tot }}\left(E_{n}\right) \cdot T\right] \int_{0}^{D_{\text {eff }}} \int_{\phi=0}^{2 \pi} \int_{\Theta=0}^{\pi / 2} \frac{d \sigma}{d \Omega}\left(E_{n}\right) d t d \Omega$ 
TABLE 1

STOPPING PONER VALUES OF PROTONS IN TISSUE

\begin{tabular}{ccc}
$\begin{array}{c}\text { Proton } \\
\text { Energy (keV) }\end{array}$ & $\begin{array}{c}\mathrm{dE} / \mathrm{dx}(\mathrm{keV} /, \mathrm{mm}) \\
(\operatorname{Ref} .18)\end{array}$ & $\begin{array}{c}\mathrm{dE} / \mathrm{dx}(\mathrm{keV} / \mu \mathrm{m}) \\
(\operatorname{Ref} .19)\end{array}$ \\
\cline { 2 - 3 } 1 & 19.3 & 12.0 \\
2 & 27.4 & 16.0 \\
3 & 33.6 & 19.0 \\
6 & 47.5 & 28.0 \\
10 & 61.3 & 36.0 \\
20 & 80.9 & 51.0 \\
30 & 92.6 & 63.0 \\
60 & 105.7 & 90.0 \\
80 & 104.7 & 100.0 \\
100 & 100.8 & 95.0 \\
200 & 76.1 & 77.0 \\
300 & 60.1 & 62.0
\end{tabular}


where $D_{\text {eff }}\left(\mathrm{mg} / \mathrm{cm}^{2}\right)$ was determined from the area seen by the incident neutrons and by the mass of the gas.

It is clear irom equation (6) that only part of the recoil protons generated in the wall reach the gas. The probability of reaching the gas depends on the point of interaction, $t\left(\mathrm{mg} / \mathrm{cm}^{2}\right)$, and on the initial proton energy $E_{p}$. This energy depends on the incident neutron energy, $E_{n}$, and the scattering angle $\theta$ in the following way:

$E_{p}=E_{n} \cdot \cos ^{2} \Theta$

The proton reaches the gas only if its range, $R_{\mathrm{p}^{\prime}}$ is greater than $t / \cos \Theta$. If the range $R_{p}$ is greater than $t_{l}=t / \cos \theta+D_{\text {eff }} \cos \theta$, the proton is not stopped in the gas and deposits an amount cf energy corresponding to a proton range of $R_{p}-t_{1}$. The wail thickness, $T$, was divided into 100 equally spaced intervals, and the neutron was allowed to interact with equal probabiiity in each of these intervals. The proton was also allowed to be scattered into any angle between 0 and $\Theta_{\max }(t)$ with a probability given by the product $\sin \Theta \cos R$ [see equations (4) and (6)]. A similar procedure was applied to interactions in the gas. However, any interaction in the gas leads to some energy deposition.

The calculations were performed for two sets of stopping power values of tissue. The first set was derived using stopping power values for $\mathrm{H}, \mathrm{C}, \mathrm{N}$, and O given by Andersen and Ziegler, (18) and the second set was that of Auxier et al, (19) with the Northcliffe and schilling extrapolation (20) at low proton energies. The two sets nearly overlap beyond a proton energy of $200 \mathrm{keV}$ as is evident in Table 1 . However, at low proton energies, the $\mathrm{dE} / \mathrm{dx}$ values given by Andersen and ziegler are higher than those given by Auxier et al.

The energy deposited by the protons in the gas was found by a range-energy relation which was parameterized from the $\mathrm{dE} / \mathrm{dx}$ values either of Andersen and ziegler $(18)$ or of those used by Auxier et al. (19) The parameterized relation with $\mathrm{dE} / \mathrm{dx}$ values from Andersen and Ziegler is given as follows:

$R_{p}\left(E_{o}\right)\left(\mathrm{mg} / \mathrm{cm}^{2}\right)=\begin{array}{lc}0.507 \mathrm{E}_{\mathrm{o}}^{0.587} & 0 \leq E \leq 0.1 \mathrm{MeV} \\ 0.093+2.09 \mathrm{E}_{\mathrm{o}}^{1.727} & E>0.1 \quad \mathrm{MeV}\end{array}$. 
The parameterized relation with $\mathrm{dE} / \mathrm{dx}$ values from Auxier et al was given by:

$R_{p}\left(E_{o}\right)\left(m g / c m^{2}\right)=$

$$
\begin{array}{ll}
0.548 E_{0}^{0.508} & 0 \leq E_{0} \leq 0.1 \mathrm{MeV} \\
0.136+2.005 E_{0}^{1.767} & E_{0}>0.1 \quad \mathrm{MeV}
\end{array}
$$

The energy deposited by a proton depends on its energy upon entering the chamber and on its trajectory length in the gas.

The protons were grouped in deposition energy bins of $1 \mathrm{keV}$ width to form a distribution $F\left(E_{p}\right)$ and were divided into four categories similar to those suggested by Caswell. (10) These include

a. Protons generated in the wall that completely traverse the gas.

b. Protons generated in the wall and stopped in the gas.

c. Protons generated in the gas that escape the gas.

d. Protons generated in the gas and stopped in it.

The program also calculated the total number of protons that deposit a significant amount of energy ( $>1 \mathrm{keV}$ ) in the gas, and also the average track length of protons in the gas, $\mathrm{D}_{\text {ave' }}$ given as follows:

$D_{\text {ave }}=\left(\sum_{i=1}^{n} p_{i} l_{i}\right) / N$

where $p_{i}$ is the probability that a proton deposits a significant energy in the gas, $l_{i}$ is its track length, and $N$, the total number of protons depositing some energy in the gas, is given by:

$N=\sum_{i=1}^{n} p_{i}$

The distribution of protons as a functioin of the deposited energy in the gas, $F\left(E_{p}\right)$, was folded with the energy resolution of the detector and the electronic system. The energy resolution can be expressed as follows: 
$w^{2}=w_{N}^{2}+w_{M}^{2}+w_{e}^{2}$

where $W$ represents the full width at half maximum (FWHM), $W_{N}$ is the contribution from the statistical nature of the formation of ion pairs in the gas, $W_{M}$ is the contribution from the gas multiplication process, and $\mathrm{w}_{\mathrm{e}}$ is the contribution from electronic noise. The tissue equivalent chambers hiave an internal ${ }^{244} \mathrm{~cm}$ alpha source. It was difficult to estimate the energy resolution from this source, because there is some broadening caused by the source finite thickness. To account for the energy dependence of detector resolution, equation (13) was written as:

$\dot{\mathrm{w}}^{2}=\mathrm{w}_{\mathrm{e}}^{2}+\mathrm{a}\left(\mathrm{E}_{\mathrm{p}}\right)$

where $E_{p}$ is the proton deposition energy in the gas. We was estimated to be 3 kev, and the function $a\left(E_{p}\right)$, derived from studies of Byrne, $(21,22)$ was given by:

$a\left(E_{p}\right)=0.028 E_{p}+1.6$

where $\mathrm{E}_{\mathrm{p}}$ is in keV. Equation (14) leads to a FWHM of about $33 \%$ and $6 \%$ at proton energy depositions of $10 \mathrm{keV}$ and $60 \mathrm{keV}$ respectively.

The detector response $G\left(E_{p^{\prime}} E_{p}^{\prime}\right)$ was parameterized in terms of a normalized Gaussian in the form

$G\left(E_{p^{\prime}} E_{p}^{\prime}\right)=\frac{1}{\sqrt{2 \pi} \sigma} \exp -\left[\frac{\left(E_{\bar{p}} E_{p}^{\prime}\right)^{2}}{2 \sigma^{2}}\right]$,

and the observed response $f\left(E_{p}^{\prime}\right)$ was given by:

$f\left(E_{p}^{\prime}\right)=\int_{0}^{E_{p}^{\max }} F\left(E_{p}\right) G\left(E_{p}, E_{p}^{\prime}\right) d E_{p}$

where $E_{p}$ is the maximum deposited energy in each detector. The distribution 
$f\left(E_{p}^{\prime}\right)$ was then converted into the distribution in linear energy $\mathrm{f}^{\prime}\left(\mathrm{y}_{\mathrm{p}}{ }^{\prime}\right)$ where $\mathrm{Y}_{\mathrm{p}}{ }^{\prime}=\mathrm{E}_{\mathrm{p}}{ }^{\prime} / \mathrm{D}$ and $\mathrm{D}$ is the diameter of the chamber.

To summarize, the outcome of the calculations includes the following:

a. The proton energy deposition distribution, $F\left(E_{p}\right)$.

b. The broadened energy deposition distribution, $f\left(E_{p}^{\prime}\right)$,

c. The broadened energy distribution as a function of the lineal energy, $f\left(y_{p}^{\prime}\right)$.

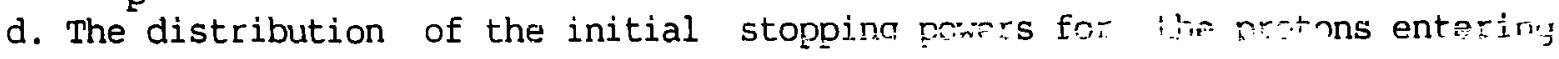
the gas or generated in the gas.

e. The distribution of track lengths of the protons that deposit a significant amount of energy in the gas.

f. The total number of protons per unit of dose equivalent.

g. The total number of protons generated in the wall that deposit a significant amount of energy in the gas.

h. The total number of protons generated in the wall and stopped in the gas.

i. The total number of protons generated in the gas.

j. The total number of protons generated in the gas and stopped in it.

\section{I. EXPERIMENTAL CONSIDERATIONS}

\section{A. Detectors}

Two spherical tissue equivalent detectors, manufactured by Far west Technology (Goleta, CA), were irradiated simultaneously. The detectors werp of Rossi type with a diameter of $5.7 \mathrm{~cm}$. They were filled with a Rossi type gas composition. (11) The gas comprised $\mathrm{H}, \mathrm{C}, \mathrm{O}$, and $\mathrm{N}$ in mass percentages of 10.2, 45.6, 40.7, and 3.5 respectively. This inixture has a somewhat different composition in carbon and oxygen than muscle tissue, (15) but the differences are insignificant for the purpose of this study. The chambers were contained in an aluminum can, $1.6 \mathrm{~cm}$ thick, which served as a vacuum tight container. The walls were made of Shonka A-150 materjal, $3.2 \mathrm{~mm}$ thick. Each detector contained a magnetically operated ${ }^{244} \mathrm{Cm}$ alpha particle source with an energy of $5.8 \mathrm{MeV}$. This source was used to calibrate the gain of the chamber and the electronic system. 
Pressures of 6.4 and $25.6 \mathrm{~mm} \mathrm{Hg}$ were used to simulate tissue thicknesses of 0.5 and $2 \mu$ respectively. The gas density is $1.04 \times 10^{-3} \mathrm{~g} / \mathrm{cm}^{3}$ (at $20^{\circ} \mathrm{C}$ and 1 atm).

The characteristic energy loss, $\mathrm{dE} / \mathrm{dx}$, for $5.8 \mathrm{MeV}$ alpha particles in a Russi type gas has two different values in the literature. Northcliffe and Schilling (20) published a value of $0.91 \mathrm{MeV} / \mathrm{mg} / \mathrm{cm}^{2}$, whereas Andersen and ziegler (23) published a value of $0.83 \mathrm{Mev}, \mathrm{mg} / \mathrm{cm}^{2}$. For this study we adopted a value of $0.91 \mathrm{MeV} / \mathrm{mg} / \mathrm{cm}^{2}$. The uncertainty in this choice does not affect the major conclusions of the present study.

The 0.5 and $2 \mu$ detectors were operated at voltages of 550 and $700 \mathrm{~V}$ respectively. Tile grids were operated at about $80 \%$ of the anode voltage. Each detector was coupled to a Canberra 2003B preamplifier whose output was connected to an ortec 572 shaping amplifier. The overall gain of the two detection systems was identical, and the ${ }^{244} \mathrm{Cm}$ alpha pulse height was abut 3.5 volts.

B. Irradiations with Monoenergetic Neutrons $\mathrm{jr}$ the Energy Range of $10 \mathrm{keV}$ to 1 MeV Using the ${ }^{7} \mathrm{Li}(\mathrm{p}, \mathrm{n})^{7}$ Be Reaction

Monoenergetic neutrons in the range of $10 \mathrm{keV}$ to $1 \mathrm{MeV}$ were prodiced using a $3 \mathrm{MV}$ Van-de-Graaff accelerator and the ${ }^{7} \mathrm{Li}(p, n)^{7}$ Be reaction. Proton energies varied between 1.95 and $2.8 \mathrm{MeV}$. The target consisted of $100 \mathrm{~g} / \mathrm{cm}^{2}$ of lithium evaporated onto a $0.5 \mathrm{~mm}$ thick tungsten disk. The other materials between the target and the detectors were 1-2 mum of stainless steel and a Freon cooling jacket. The beam tube was $5 \mathrm{~cm}$ in diameter with stainless steel walls, $4 \mathrm{~mm}$ thick. Botr. the tungsten backing and the surrounding stainless steel material caused some scattering of neutrons at low energies. This scattering effect for neutron energies $10-50 \mathrm{keV}$ is later discussed in the paper. The experimental configuration is shown in Fig. 2.

The main fluence calibration was achieved by using a long ccunter developed by East and walton. (24) The long counter is a polyethylene cylinder, $22.9 \mathrm{~cm}$ long and $22.9 \mathrm{~cm}$ in diameter. A single ${ }^{3}$ He proportional detector, pressurized to 6 atm was embedded along the symmetry axis of the cylinder. The absolute efficiency of this detector was measured by Evans. (25) Although Evans found an intrinsic efficiency peaking slightly at $450 \mathrm{keV}$ neutron energy, we used an energy averaged ef:iciency constant over the entire energy range. The efficiency adopted was $10 \%$ lower than the value measlired for the ${ }^{252}$ Cf source. 
Using an NBS calibrated ${ }^{252}$ C'f source whose strength was $2.1 \times 10^{5} \mathrm{n} / \mathrm{sec}$, the absolute efficiency for this source was $(0.020 \pm 0.002)$ and the effective center was $8 \mathrm{~cm}$ from the front surface. Because the long counter was positioned at 350 cm from the target, the effective center was considered crnstant over the neutron energy range of $100 \mathrm{keV}$ to $1.2 \mathrm{MeV}$. During the experiments, the integrated beam current .was also recorded and served as an additional calibration whenever the proton energy remained constant.

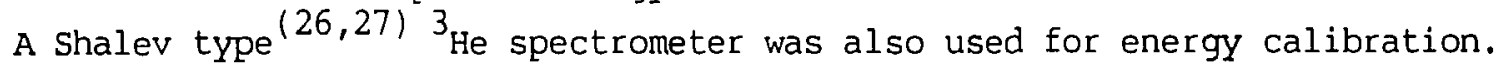
This detector is a cylindrical gridded ionization chamber, $15 \mathrm{~cm}$ long and $5 \mathrm{~cm}$ in diameter. The chamber is pressurized with a mixture of helium-3, argon, and methane at $4.2 \mathrm{~atm}$. Its reso:.ution was $30 \mathrm{keV}$ for $1 \mathrm{MeV}$ neutrons and $16 \mathrm{keV}$ for thermal neutrons. The ${ }^{3}$ He spectrometer was positioned at a distance of $120 \mathrm{~cm}$ and at $45^{\circ}$.

An Eberline NRD-1 9" sphere rem meter was used for relative dose equivalent measurements. The calibration of the NRD-l varies with the neutron energy. The efficiency expressed as counts per mrem at $100 \mathrm{keV}$ is greater by a factor of 3 than it is at $1 \mathrm{MeV}$ neutron energy. Therefore, for several irradiations when the proton energy changed, the NRD-1 was positioned at appropriate angles to keep the neutron energy incident at the detector constant. For neutron energies greater than $600 \mathrm{keV}$, the $\mathrm{NRD}-1$ was used as a complementary measure of the absolute dose equivalent. It was positioned at $120 \mathrm{~cm}$ from the target at various angles with respect to the incident beam direction.

The 0.5 and $2 \mu$ tissue equivalent chambers were positioned at the same angle, but at opposite sides with respect to the beam direction. During the experiments, angles were varied between $20^{\circ}$ and $110^{\circ}$.

Neutron energy resolution in the ${ }^{7} \mathrm{Li}(\mathrm{p}, \mathrm{n})^{7}$ Be reaction was determined mainly by two factors:

1) proton energy loss in the target and

2) the solid angle of the detectors.

The maximum energy loss of the proton in the target was about $12 \mathrm{keV}$ and 10 $\mathrm{keV}$ for proton energies of $2 \mathrm{MeV}$ and $2.8 \mathrm{MeV}$ respectively. Because the interaction probability is the same irrespective of the point of interaction in the target, the neutron energy at an angle $\Theta$ has values between $E_{n}\left(\Theta, E_{p}\right)$ and $E_{n}\left(\Theta, E_{p}-\Delta E_{p}\right)$ where $\Delta E_{p}$ is the maximum energy loss in the target.

The angle covered by the tissue equivalent chambers at the closest distance of $40 \mathrm{~cm}$ was $8^{\circ}$. The angle covered by the long counter was $3.6^{\circ}$ and the angles 
covered by the NRD-1 and ${ }^{3} \mathrm{He}$ spectrometer were $11^{\circ}$ and $7^{\circ}$ respectively. Therefore, the energy spread of neutrons incident on a detector positioned at an angle $\theta$ is between $E_{n}\left(\Theta+\Delta \Theta / 2, E_{p}-\Delta E_{p}\right)$ and $E n\left(\Theta-\Delta \Theta / 2, E_{p}\right)$, where $\Delta \Theta$ is the angle covered by the detector. For qiven values of $\Delta \mathrm{E}_{\mathrm{p}}$ and $\Delta \Theta$, the energy broadening is determined by the reaction kinematics.

At proton energies higher than $2.5 \mathrm{MeV}$, neutrons are also produced by the ${ }^{7} \mathrm{Li}(\mathrm{p}, \mathrm{n}){ }^{7} \mathrm{Be}^{*}$ reaction, where the ${ }^{7} \mathrm{Be}^{*}$ nucleus is in its first excited state $(0.43 \mathrm{MeV})$. The cross section for this reactio: increases with the increase in proton energy. At $2.8 \mathrm{MeV}$ and a neutron scattering angle of $20^{\circ}$, the ratio between the first excited and ground state transition crossisections is $12 \%$ ( 28 ) Therefore, neutron energies between $600 \mathrm{keV}$ and $1 \mathrm{c} 00 \mathrm{keV}$ produced by proton energies higher than $2.5 \mathrm{MeV}$ were contaminated by iower energy neutrons to an extent not greater than $12 \%$. Their contribution was taken into account.

C. Interference of Scattered Neutrons in the ${ }^{7}{ }_{\mathrm{J}, i}(p, n){ }^{7}$ Be Reaction

The interference of scattered neutrons with direct neutrons has been investigated. There were three reasons for scattered neutrons:

1) Scattering of neutrons from the floor.

2) Scattering of neutrons from the material surrounding the target, such as the tungsten backing, the cooling jacket, and the stainless steel vacuum pipe.

3) Neutrons generated by reactions of protons with other materials which might be present in the collimating slits, such as $\mathrm{Cr}, \mathrm{V}$, and $\mathrm{Mn}$.

In order to estimate the scattering of neutrons from the floor, a comparison was made in three different configurations. First, the chambers were completely unmasked, second they were masked with polyethylene and cadmium, except for the target direction, and third they were masked only toward the target. The proton energy was $1.95 \mathrm{MeV}$ and the chambers were mounted at $110^{\circ}$.

In order to estimate the number of neutrons that are produced prior to the interaction of che protons with the lithium target, we replaced the target with tungsten and measured the neutron yield with the long counter.

Furthermore, in order to estimate the number of scattered neutrons from the material surrounding the target, we positioned the tissue equivalent chambers at back angles where scattering of direct neutrons is kinematically forbidden. The proton energy was $1.91 \mathrm{MeV}$ and the angle was $150^{\circ}$. 
D. Neutron Fluence and Dose Equivalent Rates in the ${ }^{7}{ }^{7} i(p, n){ }^{7}$ Be Reaction

The average proton current for all experiments was $20 \mu \mathrm{A}$ and the average neutron flux emerging from the target was $3 \times 10^{8} \mathrm{n} / \mathrm{sec}$. Dose equivalent rates at the position of the tissue equivalent chambers viried between 150 and 1600 mrem/h.

Neutron fluences impinging .".2 tissue equivalent chambers, the NRD-1, and the ${ }^{3}$ He spectrometer were determined from the readings of the long counter and the differential cross section of the ${ }^{7} \mathrm{Li}(\mathrm{p}, \mathrm{n})^{7}$ Be cross section. (28) The fluence $F$, measured by the long counter, is given by:

$F\left(n / \mathrm{Cm}^{2}\right)=\mathrm{N} /(\varepsilon \cdot \mathrm{S})$

where $\mathrm{N}$ is the total counts detected by the long counter, $\varepsilon$ is the intrinsic efficiency of the long counter, and $S$ is its effective surface area. The value of $\mathrm{S}$ was $412 \mathrm{~cm}^{2}$. The fluence at an angle $\Theta$ and distance $\mathrm{d}$ from the targec, $F_{\Theta, d^{\prime}}$ is related to $F$ in the following way:

$F_{\Theta, d}\left(n / c^{2}\right)=F \cdot \frac{d_{l c}^{2}}{d^{2}} \cdot \frac{\frac{d \sigma}{d \Omega}\left({ }^{7} B e+{ }^{7} B e^{*}, \Theta\right)}{\frac{d \sigma}{d} \frac{1}{s}\left({ }^{7} B e+{ }^{7} B e^{*}, 45^{\circ}\right)}$

where $d_{l c}$ is the distance from the target to the long counter, and

$\frac{\mathrm{d} \sigma}{\mathrm{d} \Omega}\left({ }^{7} \mathrm{Be}+{ }^{7} \mathrm{Be}^{*}, \Theta\right)=\frac{\mathrm{d} \sigma}{\mathrm{d} \Omega}\left({ }^{7} \mathrm{Li}(\mathrm{p}, \mathrm{n})^{7} \mathrm{Be}\right)+\frac{\mathrm{d} \sigma}{\mathrm{d} \Omega}\left({ }^{7} \mathrm{Li}(\mathrm{p}, \mathrm{n})^{7} \mathrm{Be}^{*}\right)$

with cross sections in the laboratory system. The effect of the ${ }^{7} \mathrm{Li}(\mathrm{p}, \mathrm{n})^{7} \mathrm{Be}{ }^{*}$ reaction, which is significant only at proton energies above $2.5 \mathrm{MeV}$, was to decrease the average energy of the neutron. However, this decrease was usually smali. 
E. Monoenergetic Neutrons Using the $D(d, n){ }^{3}$ He and $T(d, n)^{4}$ He Reactions

The reactions $D(d, n)^{3}$ He and $T(d, n)^{4}$ He were carried out with a Kaman A-1001 neutron generator. The deuteron energy was $150 \mathrm{keV}$. The targets were of the form $\operatorname{TiD}_{\mathrm{X}}$ and $\mathrm{TiT}_{\mathrm{x}}$ where $\mathrm{x} \simeq 2$, and their thicknesses were about $0.59 \mathrm{mg} / \mathrm{cm}^{2}$. The neutron yields in the $D(d, n)^{3}$ He and $T(d, n)^{4}$ He reactions were about $10^{8}$ and $10^{10} \mathrm{n} / \mathrm{sec}$ respectively. The target was mounted at $120 \mathrm{~cm}$ from the floor.

The experimental configuration for the $D(d, n)^{3}$ He reaction is shown in Fig. 3. The absolute calibration of the fluence at the position of the tissue equivalent chambers was achieved by the long counter, ${ }^{(25)}$ positioned at $30^{\circ}$ with respect to the beam direction and at a distance of $308 \mathrm{~cm}$ from the target. An Eberline NRD-1 rem meter was positioned at $45^{\circ}$ and at a distance of $100 \mathrm{~cm}$. This instrument was calibrated with a ${ }^{252} \mathrm{Cf}$ source to yield 3000 counts per mrem. The tissue equivalent chambers were positioned at three different angles, $10^{\circ}, 88^{\circ}$ and $135^{\circ}$, in order to obtain their average response in the region between 2 and $3 \mathrm{MeV}$.

Differential cross sections were obtained from the report by Liskien and Paulsen. (29) Because of large energy losses of the deuteron in the target, average neutron anergies and cross sections were derived as will be discussed below.

The experimental setup for the $T(d, n)^{4}$ He reaction is given in Fig. 4 . Because of high fluxes and space limitations, the absolute fluence determination was achieved primarily by utilizing two activation foils ${ }^{63} \mathrm{Cu}$ and ${ }^{27}$ Al. The copper foil, with $69.1 \%{ }^{63} \mathrm{Cu}$ and $30.9 \%{ }^{65} \mathrm{Cu}$, was covered with cadmium in order to avoid scattered thermal neutron activation. Fast reutrons interact with copper and aluminum as follows:

$$
\begin{aligned}
& \text { 1) }{ }^{63} \mathrm{Cu}(n, 2 n){ }^{62} \mathrm{Cu} \\
& \text { 2) }{ }^{65} \mathrm{Cu}(n, 2 n){ }^{64} \mathrm{Cu} \\
& \text { 3) }{ }^{27} \mathrm{Al}(n, \alpha){ }^{24} \mathrm{Na}
\end{aligned}
$$

${ }^{62} \mathrm{Cu}$ and ${ }^{64} \mathrm{Cu}$ are positron emitters with half lives of $9.76 \mathrm{~min}$ and $12.8 \mathrm{~h}$, respectively. $\quad{ }^{24} \mathrm{Na}$ is a gamma emicter with gamma energies at $1.37 \mathrm{MeV}$ and 2.75 $\mathrm{MeV}$. The copper and aluminum foils were irradiated simultaneously at $15^{\circ}$ and at $25 \mathrm{~cm}$ from the target. The aluminum disk, $2.38 \mathrm{~g}$, was sandwiched between four copper foils, $650 \mathrm{mg}$ each. Two of them were in front of the aluminum and two in the back. 
Because 1) the abundance of ${ }^{65} \mathrm{Cu}$ is about half that of ${ }^{63} \mathrm{Cu}, 2$ ) the half life of ${ }^{64} \mathrm{Cu}$ is about 80 times longer than that of $\left.{ }^{62} \mathrm{Cu}, 3\right)$ the ${ }^{65} \mathrm{Cu}(\mathrm{n}, 2 \mathrm{n}){ }^{64} \mathrm{Cu}$ cross section is larger by about a factor of 1.7 than that of ${ }^{63} \mathrm{Cu}(n, 2 n)^{62} \mathrm{Cu}$ and, 4) the $511 \mathrm{keV}$ abundance for ${ }^{62} \mathrm{Cu}$ is greater by a factor of 5.5 than that of ${ }^{64} \mathrm{Cu}$, the activity of the copper foil at short periods after irradiation is dominated by the activity of ${ }^{62} \mathrm{Cu}$.

The arnihilation of positrons from ${ }^{62} \mathrm{cu}$ was achieved by inserting the copjer foils between two aluminum layers, each $4.5 \mathrm{~mm}$ thick, or alternatively by inserting them between two lead layers, each $1.2 \mathrm{~mm}$ thick. This amount of material was necessary to obtain the complete annihilation of positron energies up to $2.9 \mathrm{Mev}$. The copper activity was determined with two Ge(Li) detectors within a period of up to 30 minutes after irradiation. These detectors were calibrated with point gamma sources while aluminum or lead layers were positioned between the source and detector. It should be emphasized that the copper foils covered with annihilacor material are extended $511 \mathrm{keV}$ gamma ray sources and not point sources. The effect of the source size was checked by moving the foils to larger distances from the detector. The size effect was taken into consideration in all calculations.

The 24 Na activity was also measured with a Ge(Li) detector, by positioning the aluminum foils between 3 and $4 \mathrm{~cm}$ from the detector. Activation was determined by counting both peaks of ${ }^{24} \mathrm{Na}$ at 1.27 and $2.74 \mathrm{MeV}$.

Very good agreement was obtained between the fluxes derived from the copper and aluminum activation measurements.

F. The Determination of the Energy Loss of the Deuteron in the $\mathrm{TiD}_{2}$ and $\mathrm{TiT}_{2}$ Targets and of the Average Cross Sections

When the deuterons pass through $\mathrm{TiD}_{2}$ or $\mathrm{TiT}_{2}$ targets, they lose energy by coulombic interactions, thus the deuteron energy spectrum is effectively broadened. Because the differential cross section for both $D(d, n)^{3}$ He and $T(d, n)^{4}$ He raactions varies with the deuteron energy, it was necessary to extract the average deuteron energy and the average neutron energy at scattering angles of interest. Calculations were performed in order to find these quantities. The deuteron was traced along its path in the target, and for constant increments of energy loss, $\Delta E_{i}$, the corresponding path length $\Delta R_{i}$ was recorded. The energy of the deiteron at a depth $t$ in the target, after $n$ intervals, is 
$E_{d}-n \Delta E_{i}$. The number of deuterium or tritium atoms seen by the incident deuteron in each interval is proportional to $\Delta R_{i}$. The average differential cross

section, $\left[\frac{\mathrm{d} \sigma\left(\theta_{\mathrm{n}}\right)}{\mathrm{d} \Omega}\right]_{\text {ave }}$, for scattering angle $\Theta_{\mathrm{n}}$ is therefore given by:

$\left[\frac{d \sigma\left(\Theta_{n}\right)}{d \Omega}\right]_{a v e}=\frac{\left.\sum_{i=1}^{N}\left[\frac{d \sigma}{d \Omega}\left(\Theta_{n}, E_{d}-i \Delta E_{i}\right)\right] \Delta R_{i}\right)}{R_{\max }}$

where $\left(\theta_{n}, E_{d}-i \Delta E_{i}\right)$ is the laboratory differential cross section ${ }^{(29)}$ for scattering angle $\Theta_{n}$, deuteron energy $\left(E_{d}-i \Delta E i\right)$, and $R_{\max }$ is the total path length of the deuteron in the target.

The average energy of the deuteron $\left(E_{d}\right)$ ave was determined in a similar way:

$\left(E_{d}\right)$ ave $=\frac{\sum_{i=1}^{N} \sigma_{\text {tot }}\left(E_{d}-i \Delta E_{i}\right) \cdot \Delta R_{i} \cdot\left(E_{d}-i \Delta E_{i}\right)}{N}$

where $\sigma_{\text {tot }}\left(E d-i \Delta E_{i}\right.$ ) is the total cross section for either the $D(d, n)^{3} H e$ or the $T(d, n)$ He reactions for deuteron energy $\left(E_{d}-i \Delta E_{i}\right)$.

The energy loss of the deuteron in the $\mathrm{TiD}_{2}$ and the $\mathrm{TiT}_{2}$ targets was calculated using $\mathrm{dE} / \mathrm{d} x$ values of Andersen and ziegler, (23) assuming that the stopping power is the same for protons and deuterons with equal velocities. The ranges of the deuteron were parameterized in the form of $\mathrm{R}=\mathrm{a} \mathrm{E}^{\mathrm{C}}$ and are given in equations (23) and (24) for the $\mathrm{TiD}_{2}$ and $\mathrm{TiT}_{2}$ targets respectively.

$\mathrm{R}\left(\mathrm{mg} / \mathrm{cm}^{2}\right)=0.027 \mathrm{E}_{\mathrm{d}}^{0.597}$

$\mathrm{R}\left(\mathrm{mg} / \mathrm{cm}^{2}\right)=0.026 \mathrm{E}_{\mathrm{d}}^{0.597}$

$E_{d}$ is the deuteron energy in kev.

The average deuteron energy and the average neutron energy for different scattering angles are given in Table 2 . 
AVERAGE NEUTRON ENERGY (MeV)

Average

Deuteron

Energy

Reaction (keV)

Scattering Angle

$$
\underline{10}^{\circ} \quad \underline{30}^{\circ} \quad \underline{45}^{\circ} \quad \underline{88}^{\circ} \quad \underline{13}^{\circ} \quad \underline{15}^{\circ} \quad \underline{30}^{\circ}
$$

$\begin{array}{lllllll}\mathrm{D}(\mathrm{d}, \mathrm{n})^{3} \mathrm{He} & 110 & 2.86 & 2.81 & 2.76 & 2.48 & 2.24\end{array}$

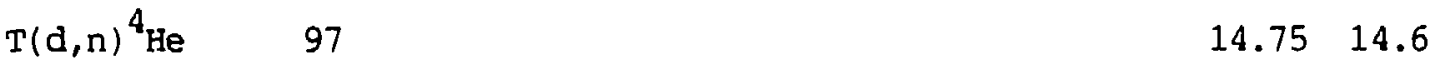

Differences shown in the average deuteron energy between the two reactions are caused by differences in the behavior of the total cross section for the two reactions as a function of the deuteron energy.

The average differential cross sections, used for $D(d, n)^{3} \mathrm{He}$, are given in Table 3 .

TABLE 3

AVERAGE $\frac{d \sigma}{d \theta}(\theta)(\mathrm{mb} / \mathrm{s} r)$ IN THE LABORATORY SYSTEM

Reaction

Scattering Angle

$\underline{10}^{\circ} \quad \underline{30}^{\circ} \quad \underline{45^{\circ}} \quad \underline{88}^{\circ} \quad \underline{135^{\circ}}$

$D(d, n)^{3} \mathrm{He} \quad 1.37 \quad 2.18 \quad 0.977 \quad 0.632 \quad 0.850$

Because the cross sections for ${ }^{63} \mathrm{Cu}(n, 2 n){ }^{62} \mathrm{Cu}$ and ${ }^{27} \mathrm{Al}(\mathrm{n}, \alpha){ }^{24} \mathrm{Na}$ depend on the neutron energy, the average cross sections at $15^{\circ}$ neutron scattering angle were found in a similar way as the average cross section for the $D(d, n)^{3}$ He and 
$T(d, n)^{4}$ He reactions. The path lergths were folded with the neutron energies and the ${ }^{63} \mathrm{Cu}(\mathrm{n}, 2 \mathrm{n})^{62} \mathrm{Cu}$ and ${ }^{27} \mathrm{Al}(n, \alpha)^{24} \mathrm{Na}$ total cross sections. The cross section for these reactions as a function of the neutron energy were from ENDF-B IV. (30) The average cross sections at $15^{\circ}$ were $583 \mathrm{mb}$ and $116 \mathrm{mb}$ for the ${ }^{63} \mathrm{Cu}(\mathrm{n}, 2 \mathrm{r}){ }^{62} \mathrm{cu}$ and ${ }^{27} \mathrm{Al}(n, \alpha){ }^{24} \mathrm{Na}$ reactions respectively.

These cross sections, together with the differential cross sections given by Liskien and Paulsen ${ }^{(29)}$ and the activity measured, yielded the fluence at the position of the tissue equivalent chambers. For the $D(d, n)^{3}$ He reaction, the fluences at the position of the tissue equivalent chambers or the NRD-1 rem meter were derived using the average cross sections shown in Table 3 and the readings of the long counter.

\section{G. Polyenergetic Neutron Sources}

The tissue equivalent chambers were also irradiated with polyenergetic neutron sources. These sources and their dose equivalent-weighted average energies included hare ${ }^{252} \mathrm{Cf}\left(\mathrm{E}_{\text {ave }}=2.49 \mathrm{MeV}\right),{ }^{252} \mathrm{Cf}$ moderated by a $\mathrm{D}_{2} \mathrm{O}$ sphere,

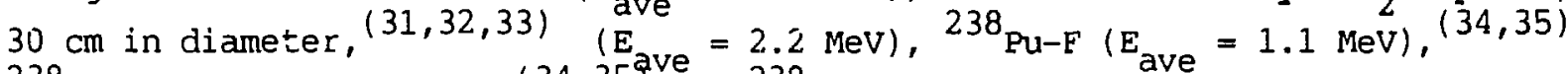
${ }^{238} \mathrm{Pu}-\mathrm{B}\left(\mathrm{E}_{\text {ave }}=2.5 \mathrm{MeV}\right),(34,35)$ and ${ }^{238} \mathrm{Pu}-\mathrm{Be}\left(\mathrm{E}_{\text {ave }}=4.5 \mathrm{MeV}\right)$. The yields of these scurces were determined using a long counter ${ }^{(25)}$ positioned at several distances from the sources. The yields are summarized in Table 4 .

TABLE 4

POLYENERGETIC NEUTRON SOURCES

\begin{tabular}{|c|c|c|}
\hline Source & $\begin{array}{l}\mathrm{E}_{\text {ave }} \\
(\mathrm{MeV})\end{array}$ & $\begin{array}{l}\text { Yields } \\
\text { (n/sec) }\end{array}$ \\
\hline${ }^{238}$ Pu-F & 1.1 & $8.57 \times 10^{6}$ \\
\hline${ }^{238}$ Pu-B & 2.5 & $1.78 \times 10^{7}$ \\
\hline${ }^{238} \mathrm{Pu}-\mathrm{Be}$ & 4.5 & $9.61 \times 10^{6}$ \\
\hline${ }^{252} \mathrm{Cf}$ & 2.4 & $5.66 \times 10^{7}$ \\
\hline
\end{tabular}


The 0.5 and $2 \mu$ chambers were irradiated simultaneously with these sources at a distance of $100 \mathrm{~cm}$.

\section{H. Extraction of Dose Equivalents From the Measured Fluences}

A discrepancy exists at several neutron energies in the values of the fluence-to-dose equivalent conversion fari:- $\dot{-}$ between ICRP-21 (Ref. 36) and NCRP-38 (Ref. 37).

In this stidy we followed the recommendations of Cross and $\operatorname{Ing}^{(38)}$ and used the values given in ICRP-21 in the region of $1 \mathrm{keV}$ to $10 \mathrm{MeV}$ whereas the value at 14.5 was taken from NCRP-38. The fluence-to-dose equivalent conversion Eactors at energies not listed in ICRP-21 were found using a linear interpolation on $a \log E_{i}, \log F_{i}$ plot, were $E_{i}$ and $F_{i}$ are the neutron energies and conversion factors of ICRP-21. The conversion factors refer to irradiations by a unidirectional broad beam of neutrons at normal incidence and are evaluated at the depth of maximum dose equivalent. The values used in this study are listed in Table 5 .

The conversion factors for ${ }^{252} \mathrm{Cf}$ and $\mathrm{D}_{2}$ O-moderated ${ }^{252} \mathrm{Cf}$ were from

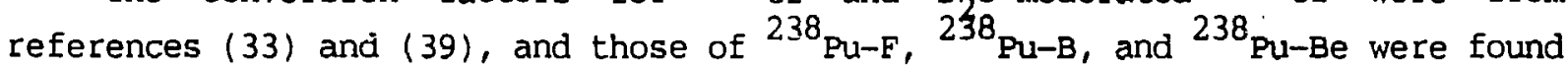
by folding the conversion factors in Table 5 with spectra published in references (33) and (34).

In the reaction ${ }^{7} \mathrm{Li}(\mathrm{p}, \mathrm{n})^{7} \mathrm{Be}$, above proton energies of $2.5 \mathrm{MeV}$, the fluence to dose equivalent conversion factors were found using the following relation:

$\underline{E}=\mathrm{b} \cdot \mathrm{f}+(1-\mathrm{b}) \mathrm{f}^{\star}$

where $f$ and $f *$ are the conversion factors for neutron energies generated in the ${ }^{7} \mathrm{Li}(\mathrm{p}, \mathrm{n})^{7} \mathrm{Be}$ (ground state) and ${ }^{7} \mathrm{Li}(\mathrm{p}, \mathrm{n})^{7} \mathrm{Be}^{*}(0.431) \mathrm{MeV}$ reactions respectively, and $b$ is the fraction of neutrons produced in the $7 \mathrm{Li}(\mathrm{p}, \mathrm{n}){ }_{\mathrm{Be}}$ (ground state) reaction. 
TABLE 5

FLUENCE-TO-DOSE EQUIVALENT CONVERSION FACTORS

Average Neutrin

Energy (keV) of Source

$10^{-9} \begin{aligned} & \text { Factor } \\ & \text { Rem } / \mathrm{n} / \mathrm{cm}^{2}\end{aligned}$

\begin{tabular}{|c|c|}
\hline 7.5 & 0.992 \\
\hline 12 & 1.08 \\
\hline 21 & 1.73 \\
\hline 44 & 3.06 \\
\hline 69 & 4.35 \\
\hline 93 & 5.47 \\
\hline 143 & 7.61 \\
\hline 194 & 9.61 \\
\hline 246 & 11.5 \\
\hline 296 & 13.3 \\
\hline 395 & 16.5 \\
\hline 495 & 19.7 \\
\hline 595 & 22.6 \\
\hline 701 & 25.3 \\
\hline 801 & 27.3 \\
\hline 899 & 30.2 \\
\hline 1012 & 32.7 \\
\hline 2500 & 40.3 \\
\hline $\begin{array}{l}14600 \\
252\end{array}$ & 57.9 \\
\hline & 33.2 \\
\hline${ }_{238}^{252} \mathrm{CE}+\mathrm{D}_{2} \mathrm{O}$ & 9.0 \\
\hline${ }^{238} \mathrm{Pu}-\mathrm{f}$ & 33.1 \\
\hline${ }^{238} \mathrm{Pu}-\mathrm{B}$ & 37.0 \\
\hline${ }^{238}{ }_{\mathrm{Pu}-\mathrm{Be}}$ & 39.7 \\
\hline
\end{tabular}




\section{A. Theoretical Results}

The primary objective of the theoretical calculations was to obtain a simple algorithm for deriving the dose equivalent from the spectra measured by low pressure tissue equivalent chambers, especially at low neutron energies (10-300 kev). Although these calculations included several simplifying assumptions, they served as a guideline for obtaining the algorithm anc for interpreting the experimental results. Even though the calculations provide a qualitative picture, they are nonetheless compared to the experimental results.

The first outcome of the calculations was a comparison between the proton recoil spectra of the 0.5 and $2 \mu$ tissue equivalent chambers. Figures 5 and 6 show the calculated spectra as a function of the lineal energy for the two chambers and for several energies in the range of $8 \mathrm{keV}$ to $69 \mathrm{keV}$. The calculations use stopping powers of Andersen and ziegler. (18) As expected the end point of each spectrum increases with incident neutron energy, but both the end point and the shape for a certain energy are vastly different between the two chambers. A similar situation occurs at $93 \mathrm{keV}$ neutron energy (Fig. 7).

The curves in Fig. 7 are normalized to the same number of incident neutrons. It can be seen that no similarity exists between the energy deposition spectra in the two chambers. The maximum lineal energy for the $0.5 \mu$ chamber is almost double that of the $2 \mu$ chamber. The spectra, especially for the $2 \mu$ chamber, do not reflect the LET of the recoiling protons. For neutron energies between 10 and $100 \mathrm{kev}$, a large fraction of the events have apparent lineal energy values below $10 \mathrm{keV} / \mu$, whereas in reality only a small fraction of the protons have LET values in this region. The ratio of the number of protons with apparent lineal energies in the region below $10 \mathrm{keV} / \mu$ to the total number of protons depositing a significant amount of energy in the gas is shown in Fig. 8 for neutron energies between 10 and $300 \mathrm{keV}$. The spectra for neutron energies below $100 \mathrm{kev}$, and especially for the $2 \mu$ chamber, reflect primarily those protons generated in the wall and stopped in the gas, or recoil protons generated in the gas that lose a great fraction of their initial energy before escaping the gas. At higher neutron energies the spectra in the two chambers are similar as is shown in Figure 9 for a neutron energy of $1 \mathrm{MeV}$. At this energy the spectra in the two chambers are similar. 
In order to show the inappropriateness of using the $2 \mu$ chamber as an LET chamber for neutron energies below $300 \mathrm{keV}$, we compared the 0.5 and $2 \mu$ in three different ways which represent the following Rossi assumptions, which are necessary and sufficient for using a tissue equivalent chamber as an LET detector:

1) The particles are generated only in the wall of the chamber.

2) The stopping power of the recoiled particles does not change significantly when the particles traverse the chamber; that is, the ranges of the particles are much longer than the diameter of the chamber.

3) The mean track length of the recoiled particles does not depend on the neutron energy, thus a lineal energy can be defined by dividing the energy deposited by an average diameter of the chamber. This dianeter is independent of the neutron energy.

Figure 10 shows the calculated ratio becween the number of protons generated in the wall and stopped in the gas, to the total number of protons generated in the wall that deposit a significant amount of energy in the gas. The calculations were carried out for two sets of $\mathrm{dE} / \mathrm{dx}$ values, adopted by Andersen and ziegler $(18)$ or by Auxier et al. (19) The calculations with both sets show that for $100 \mathrm{keV}$ incident neutron, about $25 \%$ and $100 \%$ of the protons generated in the wall in the 0.5 and $2 \mu$ chambers, respectively, are stopped in the gas. Also, quite a large percentage of the protons generated for neutron energies up to $300 \mathrm{keV}$ lose a substantial fraction of their initial energy in the gas for the $2 \mu$ chamber. Becaust the $\mathrm{dE} / \mathrm{dx}$ values of Auxier et al are lower than those of Andersen and ziegler for proton energies below $100 \mathrm{keV}$, the number of stopped protons is somewhat smaller using the first set of $\mathrm{dE} / \mathrm{dx}$ values, but is still appreciable.

Figure 11 shows the ratio between the number of protons generated in the gas and the total number of protons generated in either the wall or the gas that deposit a significant amount of energy in the gas. For a neutron energy of 100 $\mathrm{keV}$, the fraction of protons generated in the gas is about $35 \%$ and $65 \%$ for the 0.5 and $2 \mu$ chambers respectively, and for a neutron energy of $300 \mathrm{keV}$ this fraction is about $20 \%$ and $50 \%$ for the 0.5 and $2 \mu$ chambers respectively. This fraction is somewhat smaller using the $\mathrm{dE} / \mathrm{dx}$ values of Auxier et al, because more particles are predicted to enter the chamber from the wall, whereas the 
total number of protons generated in the gas is clearly independent of tha set of stopping powers used.

Figure 12 displays the track length in the gas averaged over all protons, including those generated in the wall or in the gas (see equation 13), compared to the maximum average track length. It is seen that the average track length increases with the incident energy. At $100 \mathrm{kev}$, this average diameter is about $70 \%$ and $40 \%$ of the maximum for the 0.5 and $2 \mu$ chambers respectively. For a neutron energy of $300 \mathrm{keV}$, the ratio is still 60 \% for the $2 \mu$ chamber. Using the $\mathrm{dE} / \mathrm{dx}$ values of Auxier et al, the ratio is somewhat increased, because the track lengths for the low energy protons increase. These data indicate that the definition of lineal energy in terms of the energy deposited divided by an average diameter is not appropriate at low neutron energies.

The above results indicate that the correspondence between lineal energy, measured in both the 0.5 and the $2 \mu$ chambers, and the LET of the recoiling protons in the gas is not straightforward for neutron energies below $300 \mathrm{keV}$. The extraction of the LET spectra from the lineal energy spectra must involve complicated calculations and unfolding procedures. (10)

The approach adopted in the present study was to correlate the experimental data to the dose equivalent in terms of macroscopic parameters, rather than microscopic (such as the linear energy iransfer). This correlation should be simpie and not limited by statistical considerations beyond the intrinsic efficiency of the chambers. The approach was to correlate the total number of recoil protons which deposit a significant amount of energy in the chambers to the dose equivalent.

Figures 13 and 14 show the calculated total number of protons per mrem of incident neutrons, which deposit an energy above $10 \mathrm{keV} / \mu$ for the 0.5 and $2 \mu$ chambers respectively. The cutoff at $10 \mathrm{keV} / \mu$ was chosen since such a cutoff is necessary in field situations to avoid interference from photon interactions. It is observed that the total number of protons per mrem of neutrons oscillates around an average number of about 300 for both the 0.5 and $2 \mu$ chambers. At low energies the total number of particles decreases more rapidly in the $2 \mu$ chamber as compared to that in the $0.5 \mu$ chamber, despite the fact that the total number of recoils is much larger for the $2 \mu$ chamber. The reason is that a substantial fraction of the recoil protons for low energy neutrons occur below $10 \mathrm{keV} / \mu$ for the $2 \mu$ chamber. 
The total number of protons in the two chambers shows some ambiguity between neutron energies below $100 \mathrm{keV}$ and energies above $3 \mathrm{MeV}$. A maximum is piesent in both these energy regions. The reason for this is as follows: At low energies, the elastic cross section is large and a large fraction of the particles are generated in the gas. Also, the fluence per unit dose equivalent is high. At high neutron energies, although the elastic cross section is small and the fluence-to-dose equivalent is relatively small, the average proton energy is large and the effective thickness of the wall from which protons can reach the gas is large. It is also seen in Figs. 13 and 14 that for both chambers, the total number of recoil protons has a minimum around a neutron energy of $500 \mathrm{keV}$.

Because the total number of protons per mrem oscillates as a function of the neutron energy, some spectroscopic information should be extracted from the spectrum of the deposited energy in order to correct for this oscillatory behavior. This spectroscopic information should decrease the contribution of the number of recoil protons in the energy region below $100 \mathrm{keV}$ and above 1.5 MeV, and at the same time increase the contribution of the number of recoil protons in the region between $100 \mathrm{keV}$ and $1.5 \mathrm{MeV}$.

The spectroscopic information that was extracted is displayed in Figs. 15 and 16. These figures show the fraction of recoil protons in the region 10-30 kev $/ \mu$ compared to the total number of protons above $10 \mathrm{keV} / \mu$, for the 0.5 and $2 \mu$ chambers. It is seen that for both chambers, the above-mentioned fraction shows a maximum at low and high neutron energies, while a minimum occurs near $500 \mathrm{kev}$. It is obvious that the fraction of recoil protons in the region $>30 \mathrm{keV} / \mu$ compared to the total number of protons must show a minimum in the low and high neutron energy regions and a maximum near $500 \mathrm{keV}$. The calculated fraction above $30 \mathrm{keV} / \mu$ is shown in Fig. 17 for the $0.5 \mu$ chamber.

Therefore, instead of taking the total number of particles, the dose equivalent can be represented as a linear combination of the number of particles in two regions: a) (10-30) $\mathrm{keV} / \mu$ and b) $930-120) \mathrm{keV} / \mu$, as follows:

$\mathrm{DE}($ mrem $)=\frac{\mathrm{aN}(10-30 \mathrm{keV} / \mu)+\mathrm{bN}(30-120 \mathrm{keV} / \mu)}{330}$.

Parameter a should be mxch smaller than $b$, in order to decrease the contribution 
for the low and high neutron energies and increase the contribution in the region between $100 \mathrm{keV}$ and $1.5 \mathrm{MeV}$. Equation 26 will not describe the dose equivalent accurately at low neutron energies below $75 \mathrm{keV}$ for the $2 \mu$ chamber, because a great fraction of the recoil protons are below the cutoff energy of 10 $\mathrm{kev} / \mu$.

The extraction of the dose equivalent using equation 26 is very simple and can be easily programmed into a microprocessor-based instrument. It does not suffer from any statistical limitation beyond the intrinsic efficiencies of the chambers.

\section{B. Experimental Results}

Figures 18-21 show a comparison between the 0.5 and the $2 \mu$ chambers for several incident neutron energies. The overall gains (per kev/ $\mu$ ) and the dose equivalents are the same for both chambers. It can be seen that the experiments follow qualitatively the shapes of the spectra and differences predicted theoretically by taking into account only elastic scattering with hydrogen atoms. A dramatic difference is shown between the two chambers at $44 \mathrm{keV}$ (Fig. 18), but the difference is also noticeable at a neutron energy of $300 \mathrm{keV}$ (Fig. 20). The two chambers yield nearly the same spectra at a neutron energy of 900 $\mathrm{keV}$ (Fig. 21). It should be noted that the $44 \mathrm{keV}$ spectra include a scattering component. By subtracting this component, the difference between the two chambers is largely magnified.

Table 6 compares several spectra $\geq 300 \mathrm{keV}$ for the $0.5 \mu$ chamber. The comparison shows the fraction of particles, in $10 \mathrm{keV} / \mu$ bins, for $300 \mathrm{kev}$, ${ }^{252} \mathrm{Cf}$, and ${ }^{238} \mathrm{Pu}-\mathrm{Be}$ sources and also for $14.6 \mathrm{MeV}$. The trend is clear. The higher the incident neutron energy; the less the energy deposited by the protons in the gas, a result expected from the stopping power values of the recoil particles. 
TABLE $6^{*}$

FRACTION OF ENERGY DEPOSITED AS A FUNCTION OF LINEAL ENERGY FOR THE $0.5 \mu$ CHAMBER

\begin{tabular}{|c|c|c|c|c|}
\hline $\mathrm{keV} / \mu$ & $300 \mathrm{KeV}$ & ${ }^{252} \mathrm{Cf}$ & ${ }^{238} \underline{\mathrm{Pu}-\mathrm{Be}}$ & $14.6 \mathrm{MeV}$ \\
\hline $10-20$ & 16.9 & 43.5 & 57.7 & 65.0 \\
\hline $20-30$ & 14.3 & 22.5 & 20.5 & 16.6 \\
\hline $30-40$ & 12.5 & 12.3 & 8.9 & 6.8 \\
\hline $40-50$ & 11.9 & 7.4 & 4.8 & 3.8 \\
\hline $50-60$ & 11.1 & 4.8 & 2.7 & 2.4 \\
\hline $60-70$ & 10.5 & 3.3 & 2.0 & 1.8 \\
\hline $70-80$ & 9.6 & 2.4 & 1.4 & 1.3 \\
\hline $80-90$ & 7.9 & 1.8 & 1.2 & 1.0 \\
\hline $90-100$ & 4.5 & 1.3 & 0.5 & 0.6 \\
\hline $100-110$ & 0.9 & 0.6 & 0.2 & 0.3 \\
\hline $110-120$ & 0. & 0.1 & 0.1 & 0.3 \\
\hline
\end{tabular}

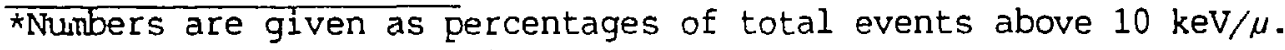

The interference of scattered neutrons with the direct neutrons was observed at neutron energies between 10 and $50 \mathrm{keV}$. The presence of scattered neutrons was most pronounced when the chambers were positioned at backward angles, such as $110^{\circ}$. At $15 \mathrm{kev}$, for instance, the neutron yield in the $2 \mu$ chamber was observed above $15 \mathrm{kev} / \mu$ (see Fig. 23), an obvious anomaly by energy conservation considerations.

The yields and spectra obtained in the chambers were similar when the chambers were completely unmasked and when they were masked from all directions except the direction of the target. When the target direction was masked, only negligible neutron yield was obtained. These experiments lead to the conclusion that the scattering of neutrons originated from the target surroundings.

When replacing the lithium target with tungsten, no neution yield was observed iri either the tissue equivalent chamber or the long counter. This means that no neutrons are produced before the protons interact with the lithium target.

When positioning the chambers at backward angles, for which scattering of neutrons is kinematically forbidden, neutron yield was observed in the two chambers. The spectra, as a function of lineal energy in the tissue equivalent chambers, clearly indicated a contribution from high energy neutrons. The yields were a significant fraction of the measurements between 10 and $25 \mathrm{kev}$.

We further performed Monte-Carlo calculations in order to estimate the 
contribution of scattered neutrons to the detection of direct neutrons between 10 and $50 \mathrm{keV}$. The Monte-Carlo calculations considered the neutrons produced by the interaction of $1.95 \mathrm{MeV}$ protons with the lithium target which scattered into the forward direction. The angular distribution of these neutrons was derived from Ref. 28. The neutrons were then allowed to elastically interact with the tungsten backing and the stainless steel surrounding the target, and the yield as a function of energy of scattered neutrons was compared with the scattering of neutrons produced by the ${ }^{7} \mathrm{Li}(\mathrm{p}, \mathrm{n})^{7}$ Be reaction. The calculations show that the contribution of scattered neutrons could be as large as 50,30 , and $15 \%$ for the measurements performed at 10,15, and $25 \mathrm{keV}$ respectively. Neutron energies varied between zero and the maximum neutron energy for the reaction (160 kev). The reason is that when the neutrons are elastically scattered by tungsten or stainless steel, they hardly change their initial energies, even if they are scattered to backward angles.

The Monte-Carlo calculations also showed that the contribution of scattering from the target vicinity into forward angles, in which neutrons with energies above $50 \mathrm{keV}$ were measured, was small compared to the yield of the direct neutrons.

The experimental data presented for the energy region between 10 and $50 \mathrm{keV}$ was corrected according to both the Monte-Carlo calculations and the calculations described in Section III. The data was also corrected for the flux removal by the material between the target and the tissue equivalent chamber. The data displayed in the following figures for these energies is the corrected data.

Figures 24 and 25 show the experimental data for the total number of particles above $10 \mathrm{keV} / \mu$ for the 0.5 and $2 \mu$ chambers, per incident dose equivalent of $1 \mathrm{mrem}$. The totâi number is normalized to 330 , the average number of particles above $10 \mathrm{keV} / \mathrm{\omega}$ per mrem. Several observations can be made. First, the total number of counts per mrem (above $10 \mathrm{keV} / \mu$ ) for both the 0.5 and $2 \mu$ chambers has maxima for both the lower energies around $70 \mathrm{keV}$ and the higher energies above $3 \mathrm{MeV}$. It also has a minimum between $300 \mathrm{keV}$ and $1 \mathrm{MeV}$. Second, the total number of particles above $10 \mathrm{keV} / \mu$ in the neutron energy region between 50 and $100 \mathrm{keV}$ is larger for the $2 \mu$ chamber, reflecting the fact that at low energies the number of interactions in the gas of the $2 \mu$ chamber is dominating. Third, the oscillatory behavior in the region of $10 \mathrm{keV}$ to $14.5 \mathrm{MeV}$ ranges within a factor of 3 for the $0.5 \mu$ chamber. A factor of 3 also exists for 
the $2 \mu$ chamber in the region of $50 \mathrm{keV}$ to $14.5 \mathrm{MeV}$. It should be re-emphasized that the energies of the sources indicated in the figures are the dose equivalent-weighted average energies, and not the fluence-weighted average energies. For instance, the dose equivalent-weighted average energy for the $\mathrm{D}_{2}$ O-moderated ${ }^{252} \mathrm{Cf}$ spectrum is $2.2 \mathrm{MeV},(32,33)$ whereas the fluence-weighted average energy for the same spectrum is $0.55 \mathrm{MeV}$ (33) For the other sources the fluence-weighted average energy is close to the dose equivalent-weighted energy.

Figures 26 and 27 show the spectroscopic information obtained from the experimental data, for the 0.5 and $2 \mu$ chambers respectively. This spectroscopic information is expressed as the ratio hetween the number of events in the (10-30) $\mathrm{keV} / \mu$ region and the total number of events above $10 \mathrm{kev} / \mu$. For both chambers this ratio peaks at low energies below $100 \mathrm{kev}$ and at high energies above $3 \mathrm{MeV}$, while it has a minimum at energies near $600 \mathrm{keV}$. Naturally, the ratio between the number of particles in the region above $30 \mathrm{keV} / \mu$ and the total number of particles peaks near $500 \mathrm{keV} / \mu$, as shown in Fig. 28 for the $0.5 \mu$ chamber.

The spectroscopic information shown in Figures 26-28 was used to derive the dose equivalent, as explained in the theoretical results. The dose equivalent was represented as a linear combination of the total number of particles in only two regions: a) $10-30 \mathrm{keV} / \mu$ and b) $30-120 \mathrm{keV} / \mu$. The dose equivalent (DE) in mrem, is expressed in the following way, for both the 0.5 and the $2 \mu$ chambers:

$D E($ mrem $)=\frac{0.33 \mathrm{~N}(10-30 \mathrm{keV} / \mu)+2.27 \mathrm{~N}(30-120 \mathrm{keV} / \mu)}{330}$.

Figures 29 and 30 display equation (27) for the experimental data between $10 \mathrm{keV}$ and $14.6 \mathrm{MeV}$. It can be observed that for e $0.5 \mu$ chamber, equation (29) represents the dose equivalent within $\pm 20 \%$ in the energy region of $25 \mathrm{keV}$ to $14.6 \mathrm{MeV}$, and for the $2 \mu$ chamber within \pm 208 in the region of $60 \mathrm{keV}$ to 14.6 $\mathrm{MeV}$. It can be concluded that, for tissue equivalent chambers corresponding to tissue diameters in the range of 0.5 to $2 \mu$, equation (27) represents the dose equivalent very well over a wide range of neutron energies. 


\section{SUMMARY AND CONCLUSIONS}

The present study was divided into two parts. The first part was devoted to theoretical calculations which took into account only elastic scattering of neutrons with hydrogen atoms in the chamber wall and in the gas. Several realistic assumptions were made to simplify the calculations. We sought to identify a simple algorithm for calculating the dose equivalent from the measured data for a wide range of neutron energies. We placed emphasis on the energy region between $10 \mathrm{keV}$ and $300 \mathrm{keV}$, since this region is of primary importance in power reactors and for most nuclear fuel processing. The algorithm was not to be microscopic, that is to derive the dose equivalent from the measurement of LET of the recoil particles in the tissue equivalent chambers. On the contrary, the calculations in the present study indicated that there is no correlation between the measured spectra as a function of the lineal energy and the LET of the recoil particles for neutron energies below $300 \mathrm{keV}$ and for chambers of $1-2 \mu$ equivalent diameter. The results are consistent with elaborate calculations carried out by Caswell. (10) we conclude that previous studies, (40) which expressed the DE for chambers with 2 tissue-equivalent diameter of $2 \mu$ as:

$D E=k \sum_{i=i_{1}}^{i_{2}} N_{i} Y_{i} q_{i}$

are in error, especially in the region below $300 \mathrm{keV}$. In Eq. 28, $\mathrm{k}$ is a normalization factor, $\mathrm{N}_{i}$ is the number of pulses accumulated in channel $i$, corresponding to lineal energy $Y_{i}$. The quantity $q_{i}$, is the quality factor corresponding to a lineal energy $Y_{i}$.

At higher neutron energies, where Rossi's assumptions can be justified, the formalism to extract the distribution of particles in LET from the distribution of particles in lineal energy involves a differentiation method which is statistically limited for operations with portable instruments.

It is shown in the present study that, for neutron energies below $300 \mathrm{keV}$ and especially for the $2 \mu$ chamber, a) the number of protons generated in the gas is a significant fraction of the total number of protons depositing energy in 
the gas, b) that the number of protons which are either stopped or lose a great fraction of their entrance energy in the gas becomes large, and c) the average track of the protons in the gas is not constant but rather increases with the neutron energy.

It should be mentioned that the calculations took into account only elastic scattering with hydrogen. These interactions are responsible for the main energy deposition in the gas. If the recoil of heavy charged particles was included, the conclusions expressed in $(a)-(c)$ in the previous paragraph could have been much more pronounced. The assumptions made by Rossi may be valid for very low pressure proportional chambers of the order of $0.1 \mu$ in equivalent diameter. Such chambers are not practical because the energy deposition is very small, thus the number of pairs created in the gas is small. In such cases the energy resolution is poor and the interpretation of the data becomes difficult.

The quantity that can be naturally measured by low pressure tissue equivalent chambers is the kerma ( $K$ ) which is expressed as follows:

$k=k_{1} \sum_{i=i}^{i_{2}} N_{i} E_{i}^{\prime}$

where $k_{l}$ is a normalization factor, $E_{i}$ is the energy deposited corresponding to channel $i$, and $N_{i}$ is the number of counts in channel $i$. However, even equation (29) is not completely accurate because the energy measured is not necessarily the deposited energy, but is the deposited energy folded with the resolution of the detertor. Also, charge equilibrium does not necessarily exists in the gas volume for low neutron energies.

The calculations carried out in this study take into account the resolution of the detector. The response was expressed in a Gaussian form. The folding is important for low deposition energies; therefore, it has more significance for the measurements of the $0.5 \mu$ chamber than for the $2 \mu$ chamber.

Two sets of $\mathrm{dE} / \mathrm{dx}$ values were used in the calculations (values derived from Andersen and ziegler and those used by Auxier et al). The values of Auxier et al are lower then those of Andersen and ziegler in the proton energy region 
between 1 and $100 \mathrm{keV}$. Although these difference led to some differences in the calculated parameters, the conclusions regarding the measurements at low neutron energies were the same.

Although the calculations contain several simplifying assumptions and provide a qualitative picture, they describe quite well the experimental data. They facilitated the development of an algorithm for calculating the dose equivalent from the measured data. The algorithm considered the total number of recoiled particles above $10 \mathrm{keV} / \mu$ divided into two regions, $10-30 \mathrm{keV} / \mu$ and $30-120 \mathrm{keV} / \mu$. These regions serve as a spectroscopic tool for correcting the response of the total number of recoiled particles per mrem of incident neutrons, which was found to be oscillating as a function of the neutron energy and ambiguous for low and high neutron energies. The dose equivalent was expressed as a linear combination of the number of particles in the $10-20 \mathrm{keV} / \mu$ and $30-120 \mathrm{keV} / \mu$ regions. The expression for the dose equivalent reproduced the dose equivalent within +208 in the region of $25 \mathrm{keV}$ to $14.6 \mathrm{MeV}$ for the $0.5 \mu$ chamber. This formalism can easily be utilized in a portable instrument without using an $A D C$.

To test the theoretical calculations, an experimental investigation of the performance of chambers with tissue equivalent diameters of 0.5 and $2 \mu$ was conducted by irradiating the chambers with monoenergetic and polyenergetic neutron sources. Monoenezgetic neutrons in the range of $10 \mathrm{keV}$ to $1 \mathrm{keV}$ were produced from the reaction $7 \mathrm{Li}(\mathrm{p}, \mathrm{n})^{7} \mathrm{Be}$, at $2.5 \mathrm{MeV}$ from $\mathrm{D}(\mathrm{d}, \mathrm{n}){ }^{3} \mathrm{He}$ and at 14.6 $\mathrm{MeV}$ with the $T(d, n){ }^{4} \mathrm{He}$ reaction. Polyenergetic sources included bare ${ }^{252} \mathrm{Cf}$, $\mathrm{D}_{2} \mathrm{O}$ - moderated ${ }^{252} \mathrm{Cf},{ }^{238} \mathrm{Pu}-\mathrm{F},{ }^{238} \mathrm{Pu}-\mathrm{B}$, and ${ }^{238} \mathrm{Pu}-\mathrm{Be}$. In most cases absolute fluences and dose equivalents were determined using a long counter of the East and walton (24) type. The experiments at energies below $300 \mathrm{keV}$ proved that the correlation between lineal energy and LET of the recoiling particles is not straightforward. The spectra, as a function of lineal energy, showed a large dependency on the equivalent tissue diameter of the chamber. At energies higher than $1 \mathrm{Mev}$, the two chambers showed similar spectra.

The efficiency of the chambers used in this study $15.7 \mathrm{~cm}$ physical diameter) is quite low. The average number of particles above $10 \mathrm{kev} / \mu$ is about 300 per mrem, which implies 0.1 counts per sec per mrem/h. In a $3 \mathrm{sec}$ integration period, the minimum dose equivalent rate to be detected with reasonable accuracy $( \pm 25 \%)$ is about $100 \mathrm{mrem} / \mathrm{h}$. For most appliations, a range from 1 to $100 \mathrm{mrem} / \mathrm{h}$ is required. Thus, low pressure spherical tissue 
equivalent chambers are not useful as dose equivalent rate meters, unless the integration period or the chamber size is significantly increased. However, they are very useful for dose equivalent measurements with a long integration period.

In order to obtain a sensitivity comparable to a SNOOPY rem meter,

i. e. 8000 counts per mrem, a tissue equivalent chamber with a diameter of about $28 \mathrm{~cm}$ is needed. This in principle is achievable but probably would be expensive. However, such an instrument would still be much lighter than a SNOOPY and less cumbersome. The instrument would measure the dose equivalent, using equation (27) to within $+20 \%$ of the expected value in the region of $25 \mathrm{keV}$ to $14.6 \mathrm{MeV}$. This is a much better response than that of a SNOOPY, (41) which over-responds by at least a factor of 2 at $25 \mathrm{keV}$, and under-responds by a factor of 3 at $14.6 \mathrm{MeV}$.

Another approach is now used by several laboratories. $(42,43)$ In this approach high pressure proportiunal chambers, filled with a hydrogen-rich mixture, are used. The recoil protons are usually stopped in the gas, and the energy deposited spectrum gives information about the incident neutron spectrum. At low neutron energies, the sensitivity of these detectors is much greater than for low pressure chambers. At high energies, such as $14.6 \mathrm{MeV}$, very high pressures are needed in order to stop most of the recoil protons.

A small, light weight, portable rem-meter, based on Eq. (27), and utilizing a $0.5 \mu$ tissue equivalent chamber, has been thoroughly field-tested. (44) The instrument is microprocess:-based with self-test circuitry for stability and calibration. The instrument displays the raw spectrum as a function of lineal energy, the dose equivalent, and the dose equivalent rate.

\section{ACKNOWLEDGMENTS}

We acknowledge the valuable assistance of Edwin Adams for operating the Van-de-Graaff accelerator and for his technical help in performing the ${ }^{7} \mathrm{Li}(\mathrm{p}, \mathrm{n})^{7} \mathrm{Be}$ experiments.

We also would like to thank J. M. Graf and M. J. Voltin for performing the Monte-Carlo calculations used to estimate the interference of scattered neutrons. 


\section{References}

1. W. Quam, T. Del Duca, W. Plake, G. Graves, and T. DeVore, "Pocket Neutron REM Meter," IEEE Tran. Nucl. Sci. NS. 29, 637 (1982).

2. W. Quam, "Progress with the Pocket REM Meter, "10th DOE Workshop on Personnel Neutron Dosimetry," Acapulco, Mexico, September 1983, (CONE-8308140, PNL-SA-12352).

3. Y. Eisen, G. Engler, E. Ovac'a, Y. Shemai, Z. Baum, and Y. Levi, "A Small Size Neutron and Gamma Dosimeter with a Single Silicon Surface Barrier Detector," 10th DOE Workshop on Personnel Neutron Dosimetry, Acapulco Mexico, September 1983 (CONF-8308140-PNL-SA-12352), p. 157.

4. W. H. Tyree and R. B. Falk, "A Personnel Neutron Dosimeter," 9 th DOE Workshop on Personnel Neutron Dosimetry, Las Vegas, June 1982 (CONF-820668, PNL-SA-10714), p. 154 .

5. B. H. Erkkila, D. A. Waechter, and D. G. Vasilik, "A Portable Neutron Spectometer/Dosimeter," 9th DOE Workshop on Personnel Neutron Dosimetry, Las Vegas, June 1982 (CONF-820668, PNL-SA-10714), p. 163.

6. H. H. Rossi and W. Rosenzweig, "A Device for the Measurement of Dose as a Function of Specific Ionization," Radiobiology 64, 404 (1955).

7. G. S. Hurst, "An Absolute Tissue Dosimeter for Fast Neutrons," British Journal of Radiology 27, 353 (1954).

8. L. W. Brackenbush, G. W. R. Endres, and L. G. Faust, "Measuring Dose and Quality Factors with Tissue Equivalent Proportional Counters," Radiation protection Monitoring, IAEA, SM-229/52, (International Atomic Energy Agency, Vienna, 1979), p. 231.

9. J. W. Baum, A. V. Kuehner, and R. L. Chase, "Dose Equivalent Meter Designs Based on Tissue Equivalent Proportional Counters," Health Physics 19, 813 (1970). 
10. R. S. Caswell, "Deposition of Energy by Neutrons in Spherical Cavities," Radiation Research 27, 92 (1966).

11. H. H. Rossi, "Microscopic Energy Distribution in Irradiated Matter," in Radiation Dosimetry, Vol. 1, F. H. Attix and W. C. Roesch, eds. (Academic Press, New York, 1968), p. 70.

12. A. Ricourt, F. Posny, R. Soulte, M. Chemtol, and V. D. Nygugen, "Possibilities d'utilization des techniques microdosimetriques poor la determination de l'equivalent de dose," Seventh symposium on Microdosimetry, Oxford, 1981, J. Booz, H. G. Ebert, and H. D. Hartfield, eds. (CONF. EUR 7147), p. 625.

13. T. G. Stinchcomb and T. B. Borak, "Neutron Quality Parameters versus Energy Below $4 \mathrm{MeV}$ from Microdosimetric Calculations," Radiation Research 93, 1 (1983).

14. G. W. R. Endres, J. M. Aldrich, L. W. Brackenbush, and R. V. Griffith, "Neutron Dosimetry at Commercial Nuclear Plants-Final Report of Subtask A: Reactor Containment Measurements," USNRC Report NUREG/CR-1769, (May, 1981).

15. International Commission on Radiation Units and Measurements, Report No. 26, "Neutron Dosimetry for Biology and Medicine," (Washington, D. C., January, 1977); p. 91 .

16. J. B. Marion and J. L. Fowler, Fast Neutron Physics, Part II (John Wiley, New York, 1963), p. 2209.

17. J. B. Marion and F. C. Young, Nuclear Reaction Analysis (North Holland, Amsterdam, 1968), p. 122 .

18. H. H. Andersen and J. F. Ziegler, "Hydrogen, Stopping Powers and Ranges in All Elements," in The Stopping and Ranges of Ions in Matter, Vol. 3 , (Pergamon Press, 1977). 
19. J. A. Auxier, W. S. Snyder, and T. D. Jones, "Neutron Interactions and Penetrations in Tissue," in Radiation Dosimetry, Vol. 1, F. H. Attix and w. C. Roesch, eds. (Academic Press, New York, 1968), p. 275.

20. L. C. Northcliffe and R. F. Schilling, "Range and Stopping Power Tables for Heavy Ions," Nuclear Data Tables A7, 233 (1970).

21. J. Byrne and F. Shaikh, "Avalanche Chain Development in an Argon Methane Proportional Counter," Nucl. Instr. Meth. 79, 286 (1970).

22. J. Byrne, "Statistics of Electron Avalanches in the Proportional Counter," Nucl. Instr. Meth. 74, 291 (1969).

23. H. H. Andersen and J. F. Ziegler, "Helium, Stopping Powers and Ranges in All Elements," in The stopping and Ranges of Ions in Matter, Vol. 4, (Pergamon Press, 1977).

24. L. V. East and R. B. Walton "Polyethylene Moderated ${ }^{3}$ He Neutron Detectors," Nucl. Instr. Meth. $\underline{72}, 161$ (1969).

25. A. E. Evans, "Energy Dependence of the Response of a 3 He Long Counter," Nuc. Instr. Meth. 199, 643 (1982).

26. S. Shalev and J. M. Cuttler, "The Energy Distribution of Delayed Fission Neutrons," Nucl. Sci. Eng. 51, 52 (1973).

27. A. E. Evans and J. D. Brandenberger, "High Resolution Fast Neutron Spectroscopy Without Time-of-Flight," IEEE Trans, Nucl. Sci. NS-26, 1484 (1979).

28. H. Liskien and A. Paulsen, "Neutron Production Cross Sections and Energies from the Reaction ${ }^{7} \mathrm{Li}(\mathrm{p}, \mathrm{n}){ }^{7} \mathrm{Be}$ and ${ }^{7} \mathrm{Li}(\mathrm{p}, \mathrm{n}){ }^{7} \mathrm{Be}^{*}$," Nuclear Data Tables 15, 57 (1975). 
29. H. Liskien and A. Paulsen, "Neutron Production Cross Sections and Energies for the Reactions $T(p, n)^{3} \mathrm{He}, D(d, n)^{3} \mathrm{He}$ and $T(d, n)^{4} \mathrm{He}$, Nuclear Data Tables 11, 569 (1973).

30. "ENDF/B-IV Dosimetry File," B. A. Magurno, ed., Information Analysis Center Report, Brookhaven National Laboratory, BNL-NCS-50446, (1975).

31. R. B. Schwartz and C. M. Eisenhauer, "The Design and Construction of a $\mathrm{D}_{2}$ 0-Moderated ${ }^{252} \mathrm{Cf}$ Source For Calibrating Neutron Personnel Dosimeters Used at Nuclear Power Reactors," NUREG/CR-1204 (January, 1980).

32. J. L. Chartier, et al, "Neutron Reference Radiations for Calibrating Neutron Measuring Devices for Radiation Protection Purposes and for Determining Their Response as a Function of Neutron Energy," in Proc. Fourth Symposium on Neutron Dosimetry, Munich, Neuherberg, June 1981, EUR 7448 , vol. 1, p. 387 .

33. R. B. Schwartz (Average Energy for ${ }^{252} \mathrm{Cf} \mathrm{D}_{2} \mathrm{O}$ moderated in Munich Conference).

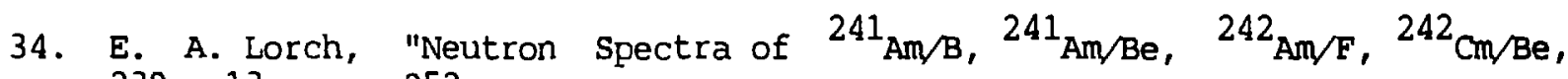
${ }^{238} \mathrm{Pu} /{ }^{13} \mathrm{C}$ and ${ }^{252} \mathrm{Cf}$ Isotopic Neutron Sources," International Journal of Applied Radiation and Isotopes 24, 585 (1973).

35. J. De Pangher and E. Tochilin, "Neutrons from Accelerators and Radijactive Sources," in Radition Dosimetry, Vol. 3, F. H. Attix and E. Tochilin, eds. (Academic Press, 1969).

36. International Commission on Radiological Protection, "Radiation Protection," ICRP Publication 21 (Pergamon Press, 1971).

37. National Council on Radiation Protection and Measurements, "Protection Against Neutron Radiation," NCRP Report No. 38 (Washington, D. C., 1971). 
38. W. G. Cross and H. Ing, "Calculations on Neutron Dosimetry at the Chalk River Nuclear Laboratory," in 8th DOE Workshop on Personnel Neutron Dosimetry, Battelle Pacific Northwest Laboratory, PNL-SA-9950 (1981), p. 163.

39. C. M. Eisenhaur, "Evaluation of Dose Equivalent Per Unit Fluence for a $\mathrm{D}_{2}$ O-moderated ${ }^{252} \mathrm{Cf}$ Neutron Source," Radiation Protection Dosimetry $\underline{9}, 63$ (1984).

40. D. G. Vasilik, B. H. Erkkila, and D. A. Waechter, "A Portable Neutron Spectrometer/Dosimeter," Radiation Protection Dosimetry 10, 121 (1985).

41. G. Tessler and S. S. Glicksicein, "Monte-Carlo Calculation of the Response of the Portisle Neutron Monitor SNOOPY," Health Phys. 28, 197 (1975).

42. T. J. Yule and E. F. Bennett, "Some Aspects of the Use of Proton Recoil Proportional Counters for Fast Neutron Personnel Dosimeters," Argonne National Laboratory report ANL/EV/AP-84-1 (1984).

43. H. Ing, W. G. Cross, and P. J. Bunge, "A Spectrometry System for Measuring Neutrons from $50 \mathrm{KeV}$ to $20 \mathrm{MeV}$," Health Phys. 39, 1064 (1980).

44. Y. Eisen, R. J. Brake, D. G. Vasilik, R. J. Littlejohn, B. H. Erkkila, D. E. Waechter and J. M. Crowell, "A Portable seutron Dosimeter Based on a Tissue Equivalent Chamber," to be published in Radiation Protection Dosimetry. 


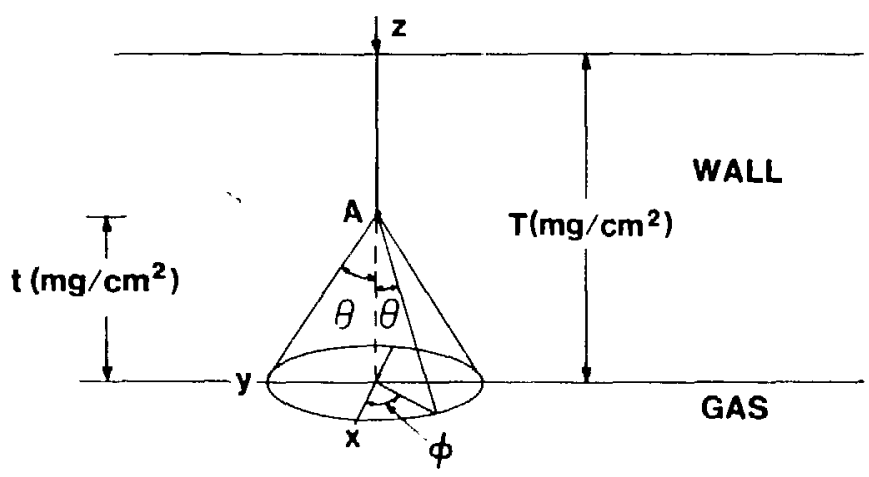

Fig. 1. Coordinate system for neutron interactions with the wall of the chamber.

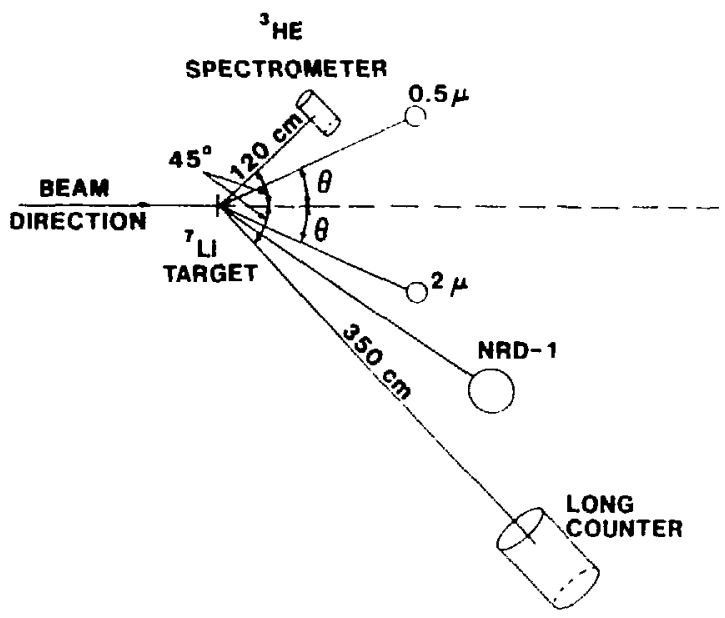

Fig. 2. Schematic diagram of the experimental setup for the ${ }^{7} \mathrm{Li}(\mathrm{p}, \mathrm{n})^{7} \mathrm{Be}$ neutron irradiation.

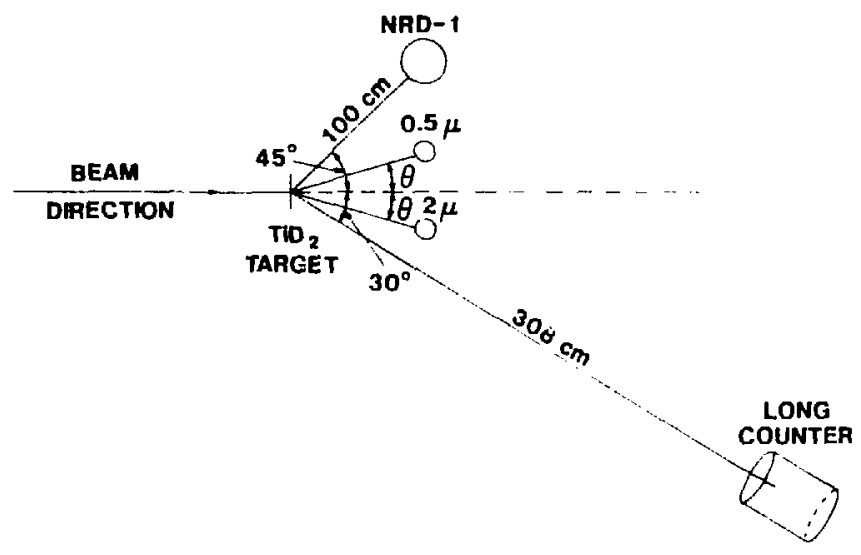

Fig. 3. Schematic diagram of the experiinental setup for the $D(d, n)^{3} \mathrm{He}$ neutron irradiations. 


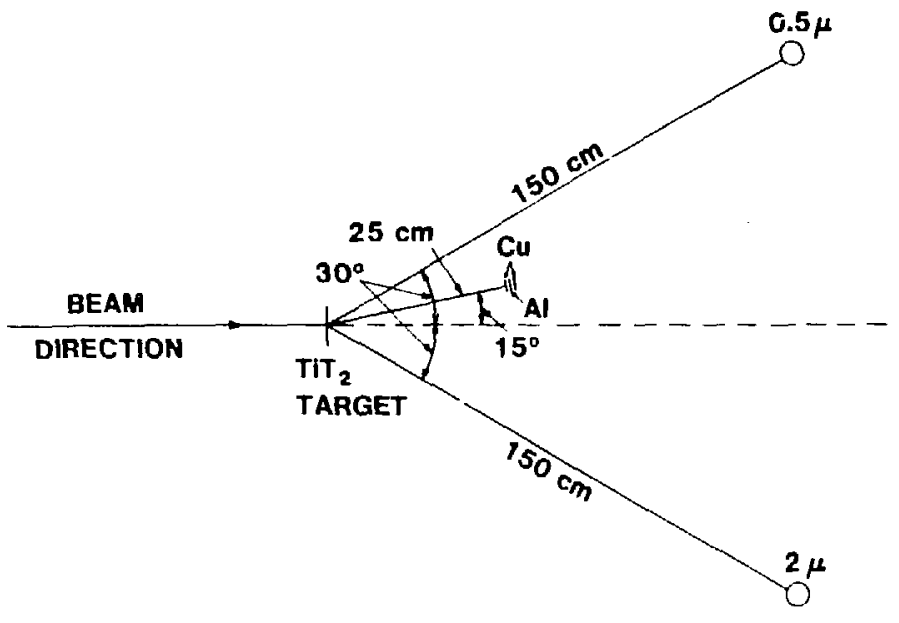

Fig. 4. Schematic diagram of the experimental setup for the $T(d, n)^{4}$ He neutron irradiations.

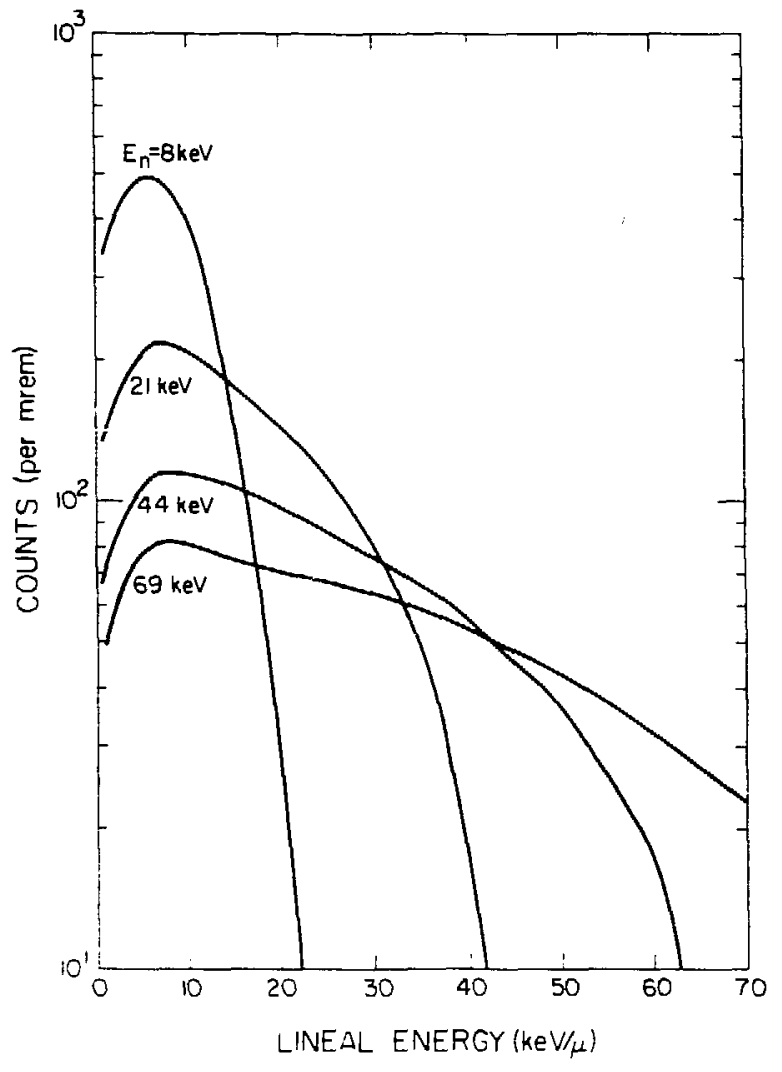

Fig. 5. Calculated energy deposition spectra of recoil protons as a function of the lineal energy for the $0.5 \mu$ tissue equivalent chamber. Incident neutron energies ranged from 8 to $69 \mathrm{keV}$ as noted.

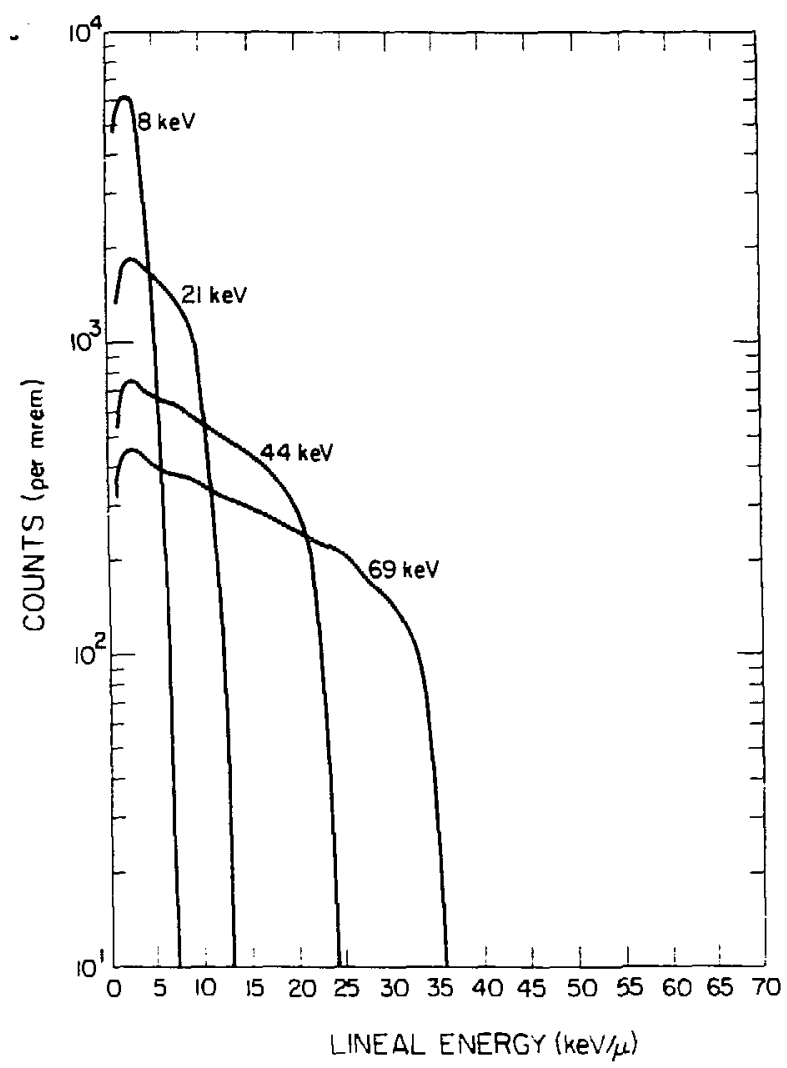

Fig. 6. Calculated energy deposition spectra of recoil protons as a function of the lineal energy for the $2 \mu$ tissue equivalent chamber. Incide:ıt neutron energies ranged from 8 to $69 \mathrm{keV}$ as noted. 


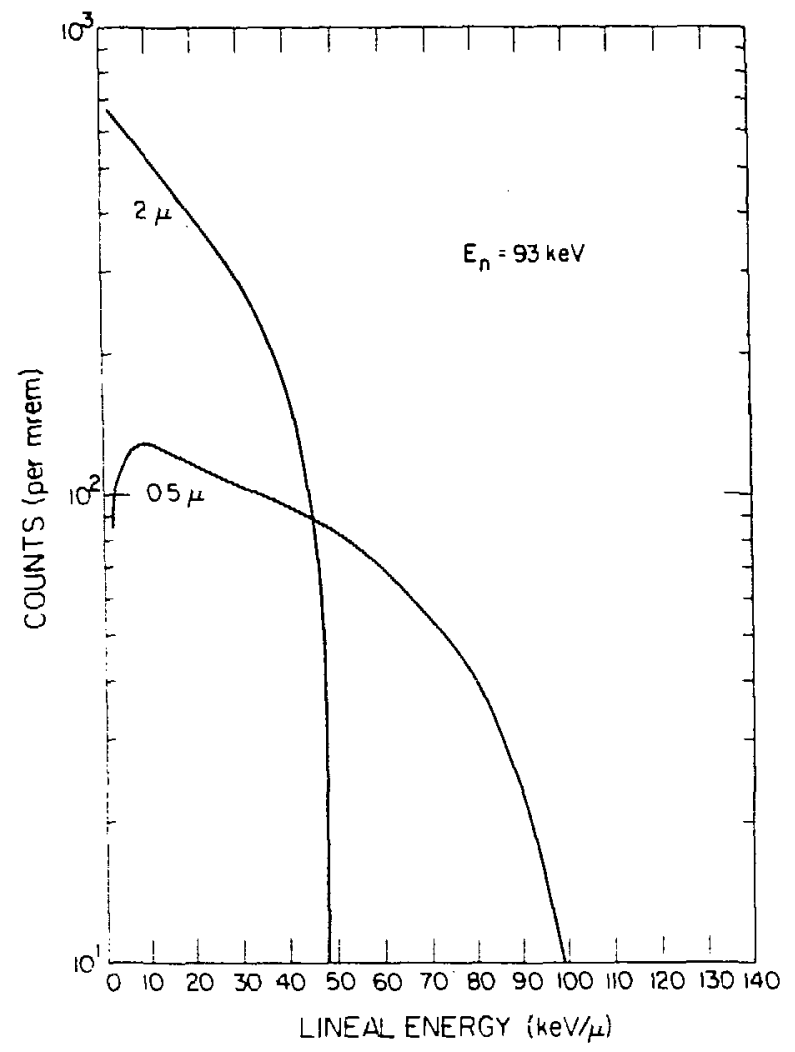

Fig. 7. Calculated energy deposition spectra of recoil protons as a function of the lineal energy for 0.5 and $2 \mu$ chambers, and for $93 \mathrm{keV}$ neutron energy (arbitrary units).

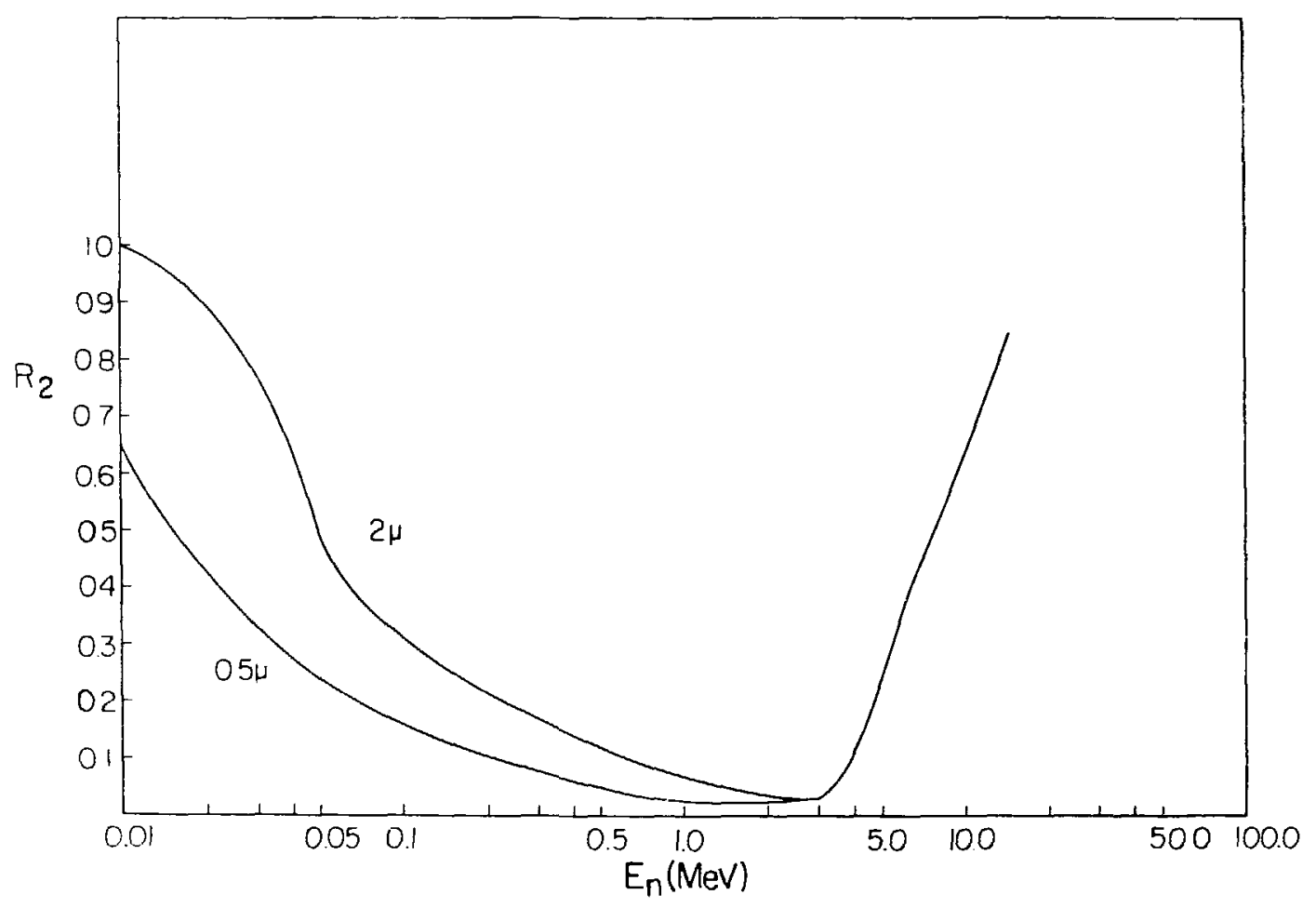

Fig. 8. Calculated ratio $\left(R_{2}\right)$ between the number of protons below $10 \mathrm{keV} / \mu$ to the total number of protons as a function of the neutron energy for 0.5 and $2 \mu$ tissue equivalent chambers. 


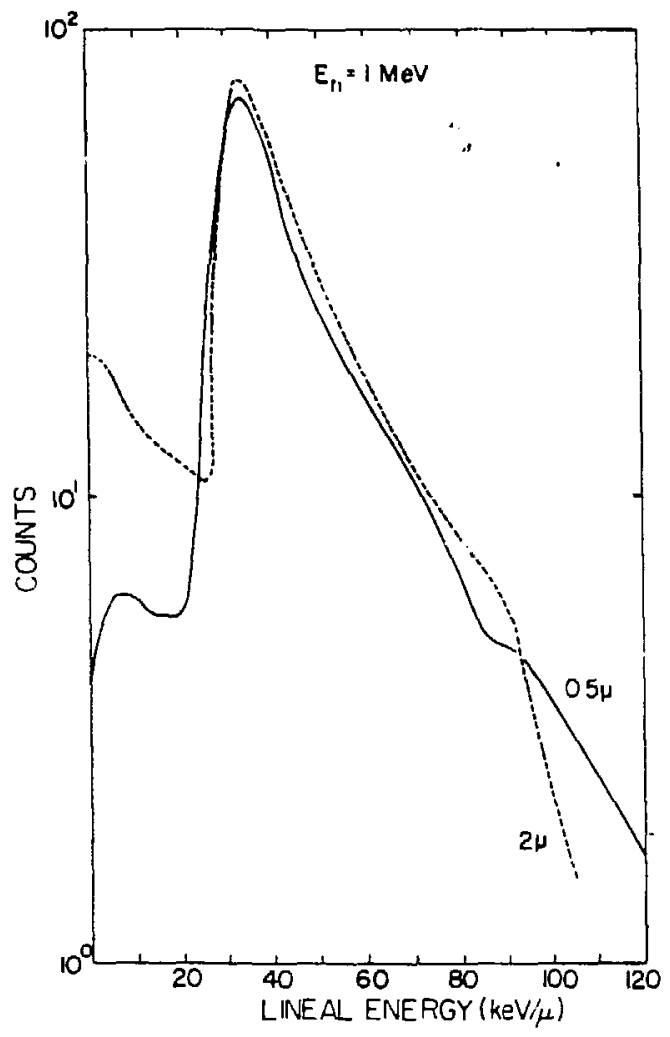

Fig. 9. Calculated energy deposition spectra of recoil protons as a function of the lineal energy for $1 \mathrm{MeV}$ incident neutrons and for 0.5 and $2 \mu$ chambers.

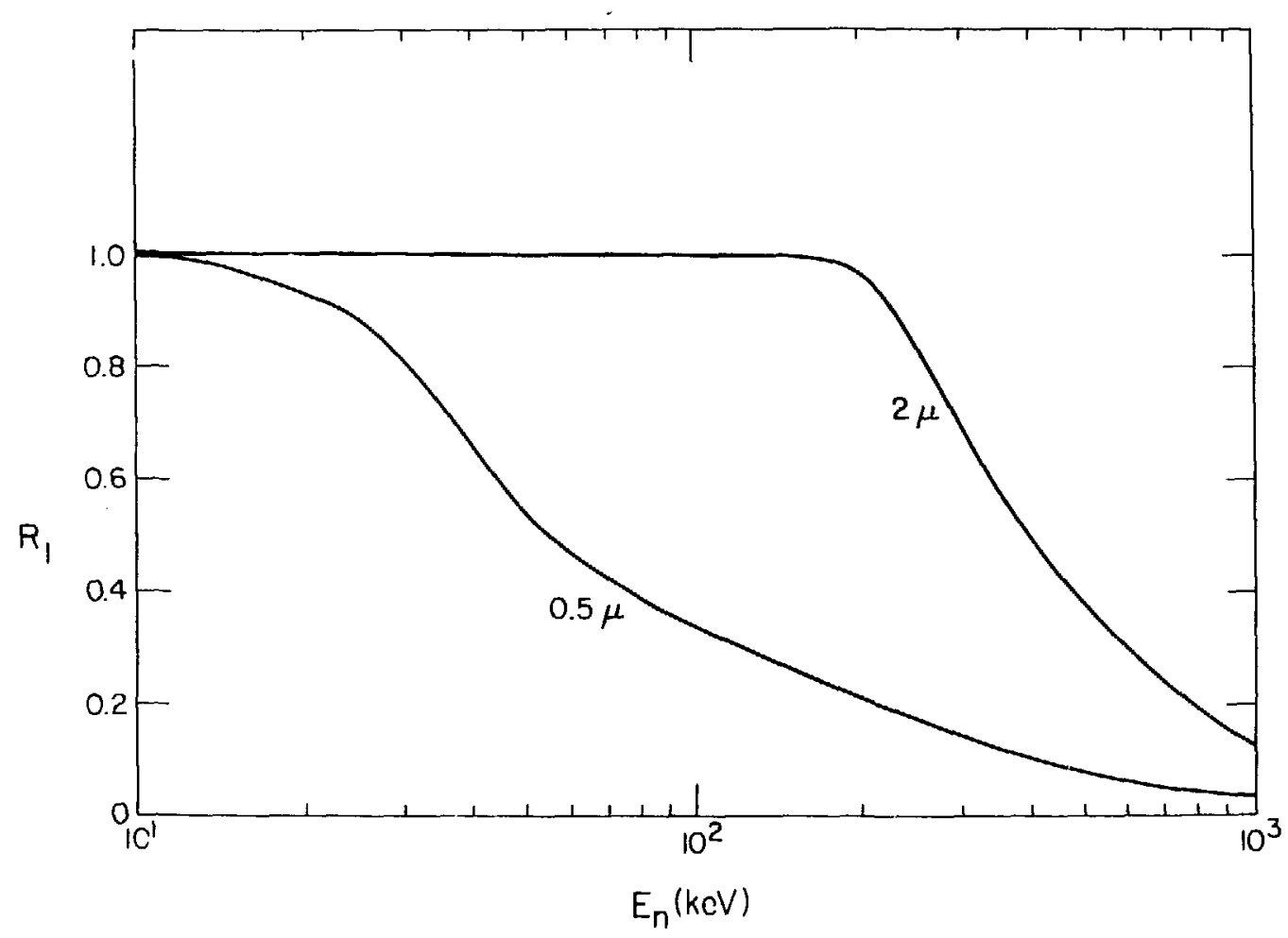

Fig. 10. Calculated ratio $\left(R_{I}\right)$ between the number of protons generated in the wall and stopped in the gas and the total number. of protons generated in the wall that reach the gas, for the 0.5 . and the $2 \mu$ chambers. 


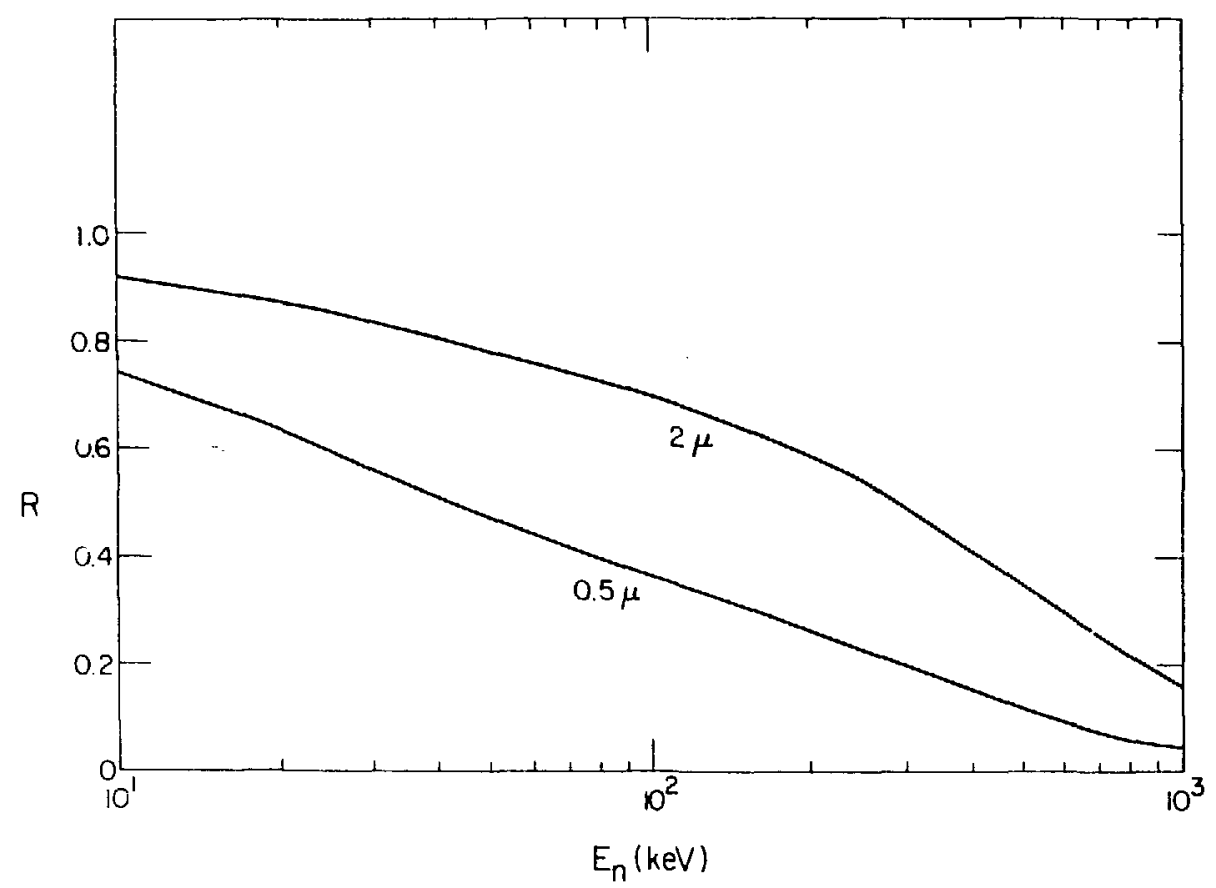

Fig. 11. Calculated ratio (R) between the number of protons generated in the gas and the total number of protons generated in both the wall and the gas, for the 0.5 and $2 \mu$ chambers.

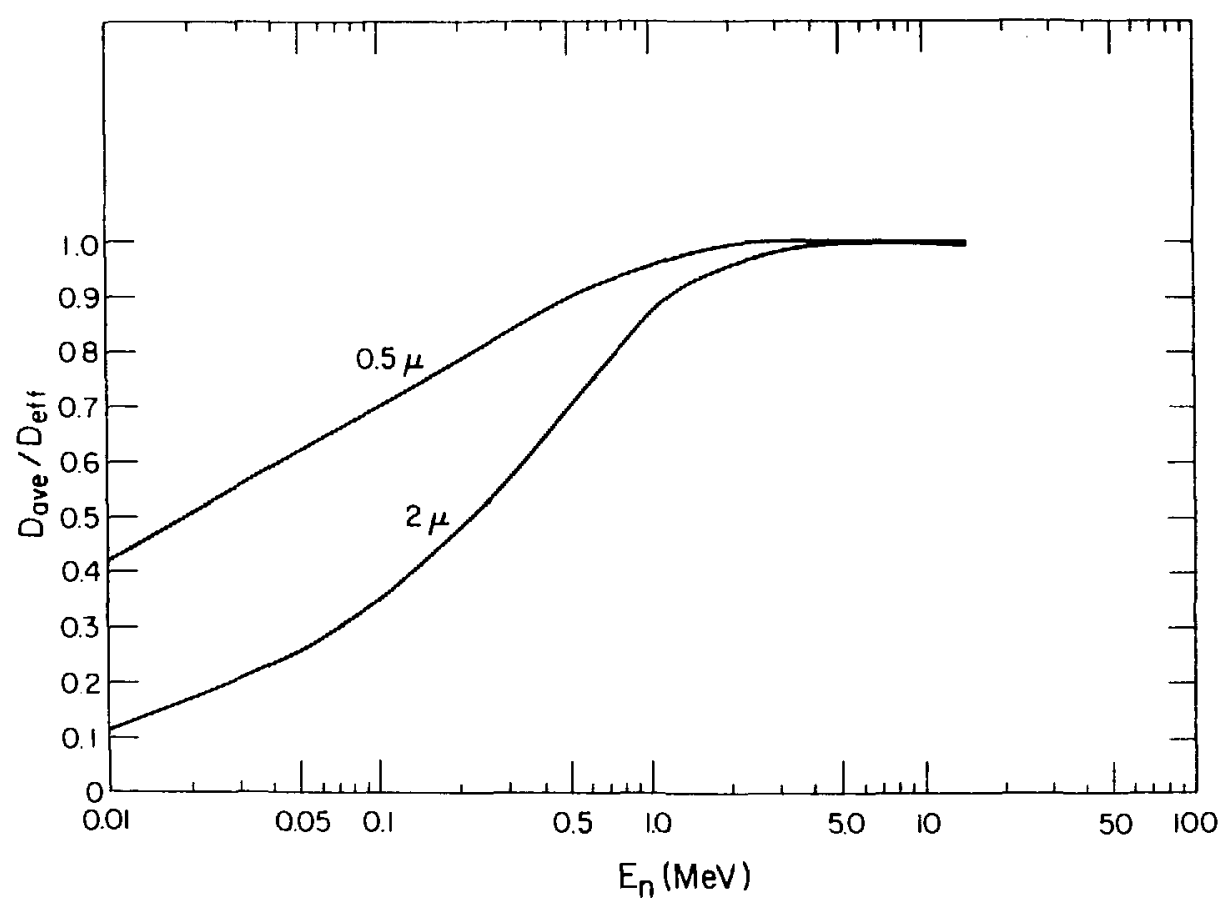

Fig. 12. Calculated ratio between the average track length $\left(D_{\text {ave }}\right)$ in the gas for recoil protons generated in both the wall and the gas and the maximum average track length $\left(D_{\text {eff }}\right)$ at high neutron energies. Calculations are for the 0.5 and $2 \mu$ chambers. 


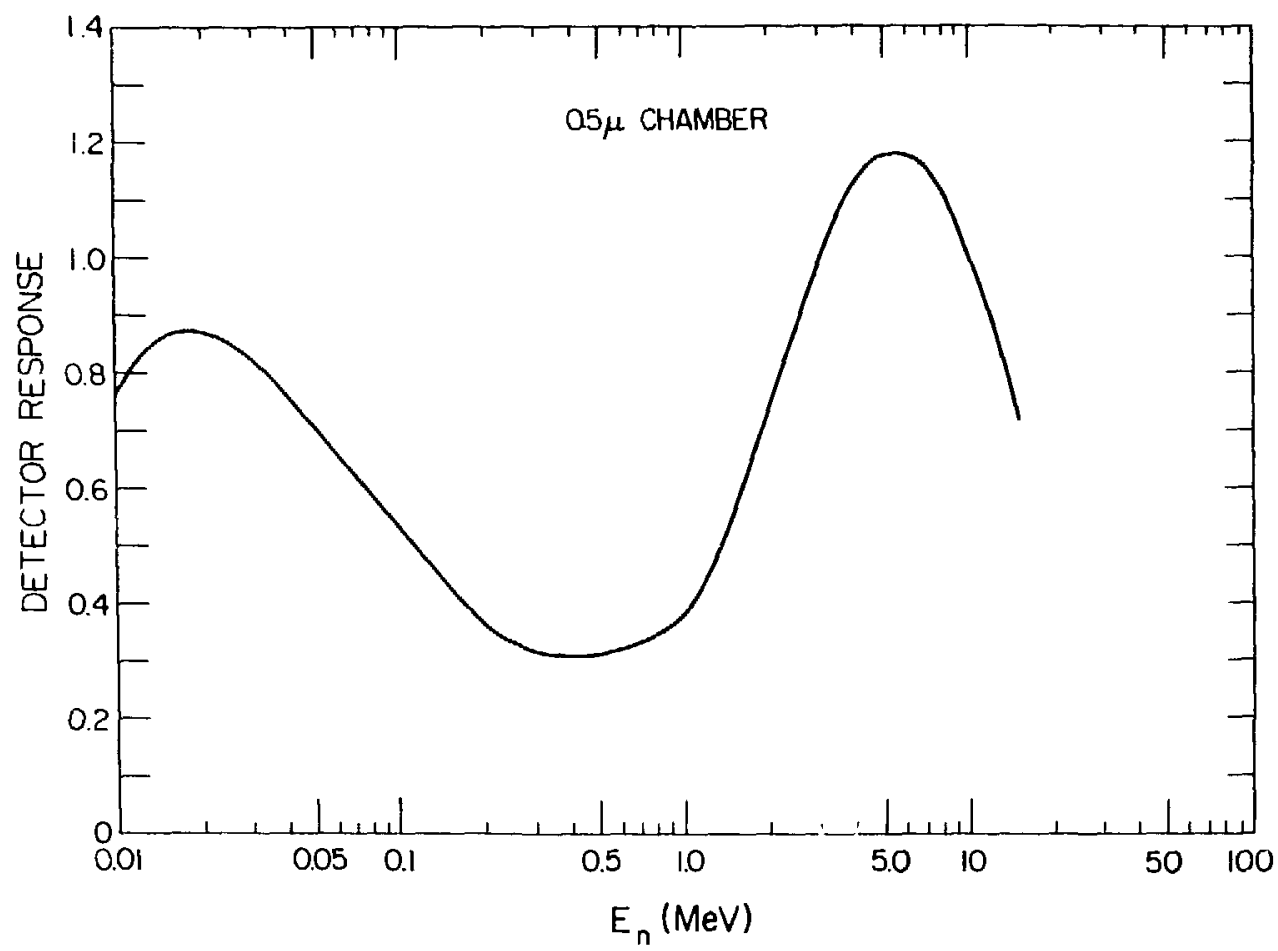

Fig. 13. Calculated detector response for the $0.5 \mu$ chamber, expressed as the number of recoil protons above $10 \mathrm{keV} / \mu$ and normalized to the average value of 330 per mrem.

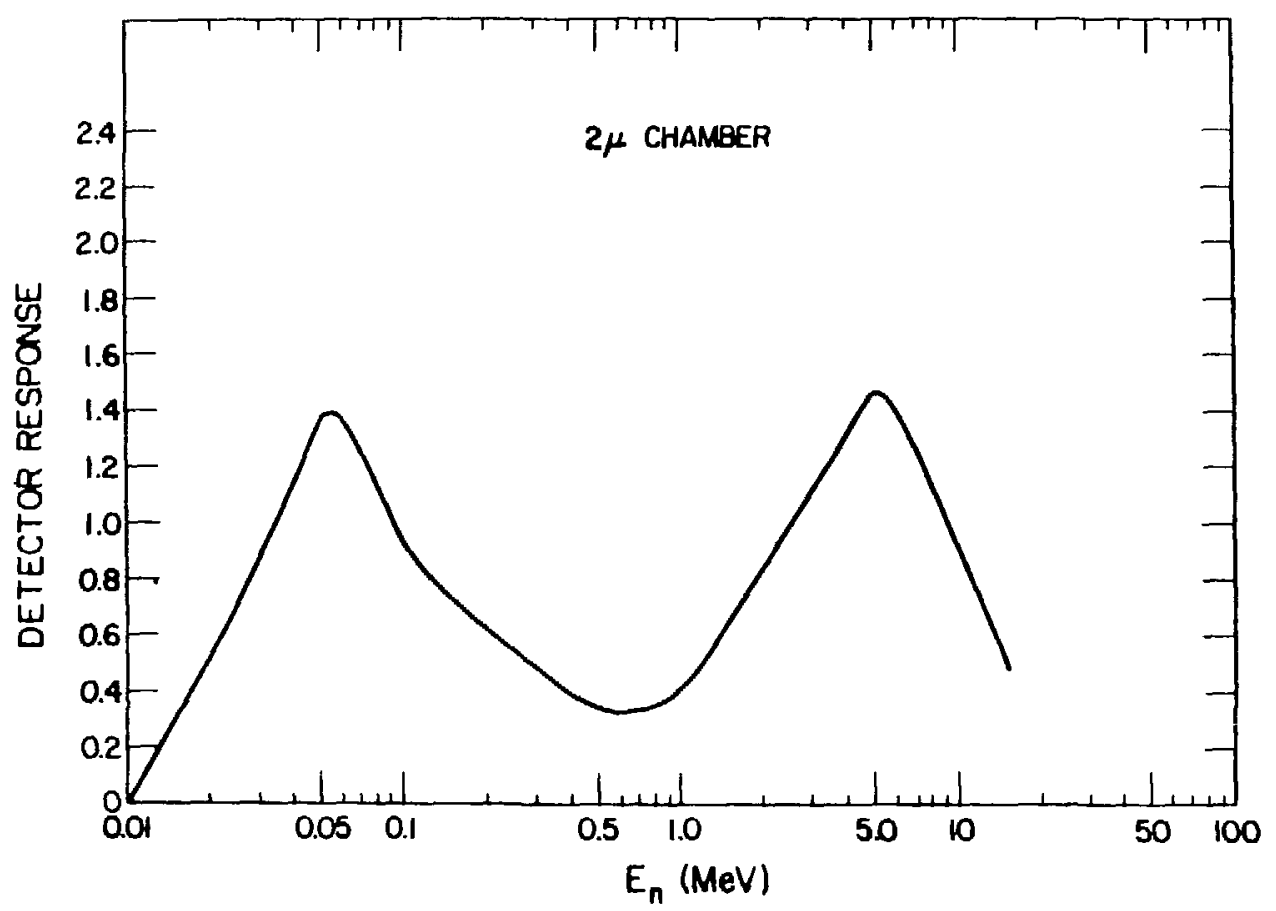

Fig. 14. Calculated detector response above an energy deposition of $10 \mathrm{keV} / \mu$ for the $2 \mu$ chamber, expressed as in Fig. 13. 


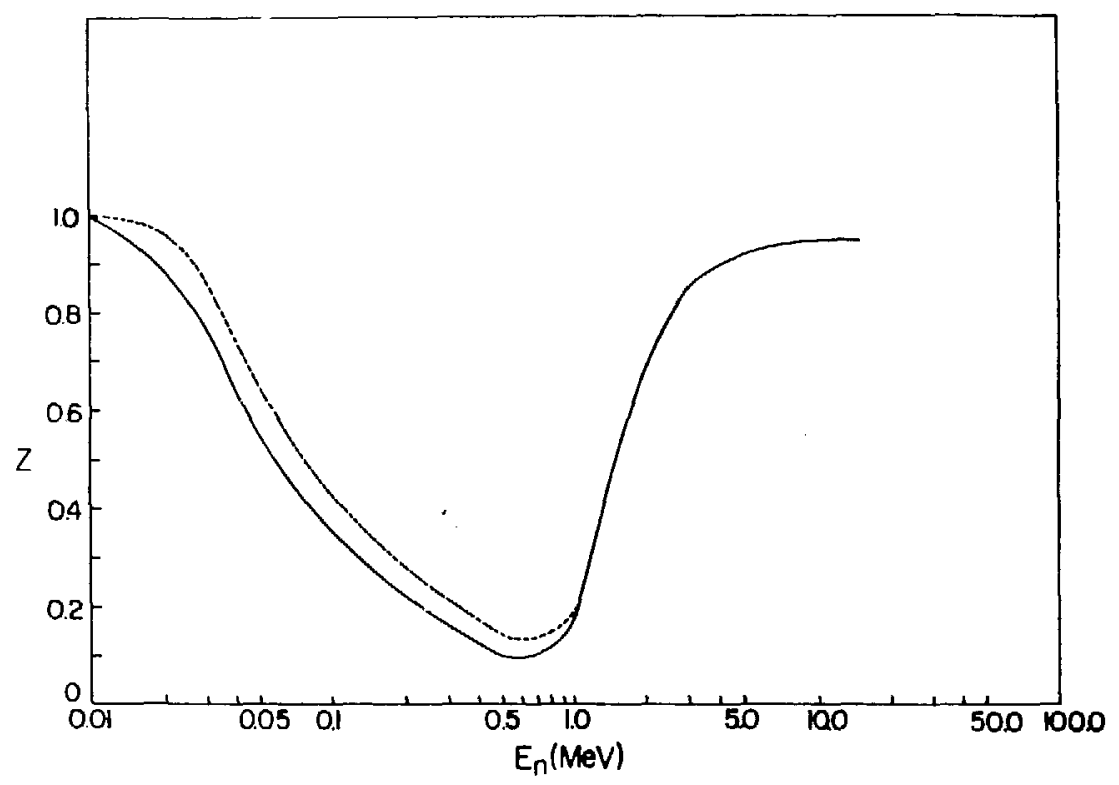

Fig. 15. Calculated ratio $(Z)$ between the number of recoil protons in the region between $10-30 \mathrm{keV} / \mu$ and the total number of recoil protons in the region of $10-120 \mathrm{keV} / \mu$, for the $0.5 \mu$ chamber. Solid and dashed lines are calculations using stopping power values from Anderson and Ziegler(18) and Auxier et a1.(19) respectively.

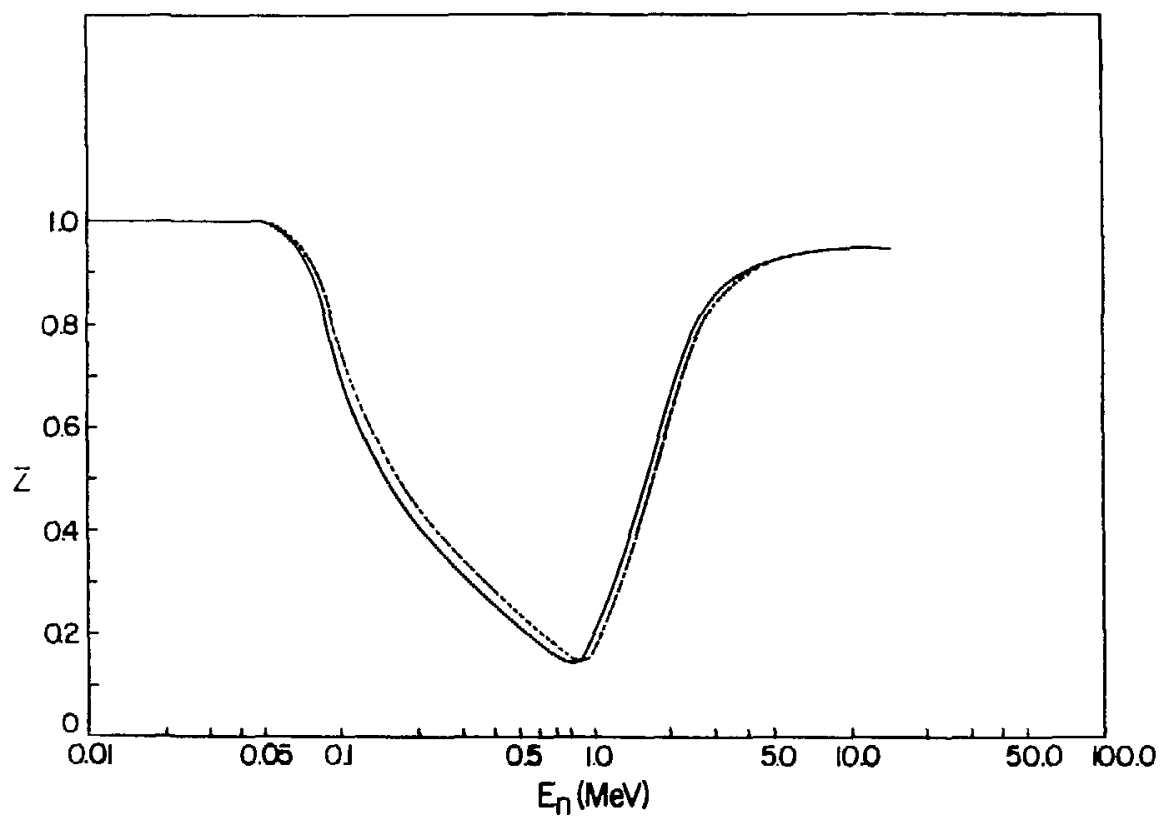

Fig. 16. Calculated ratio $(Z)$ between the number of recoil protons in the region of $10-30 \mathrm{keV} / \mu$ to the total number of recoil protons in the region of $10-120 \mathrm{keV} / \mu$, for the $2 \mu$ chamber. Solid and dashed lines are calculations using stopping power values from Anderson and Ziegler(18) and Auxier et al.(19) respectively. 


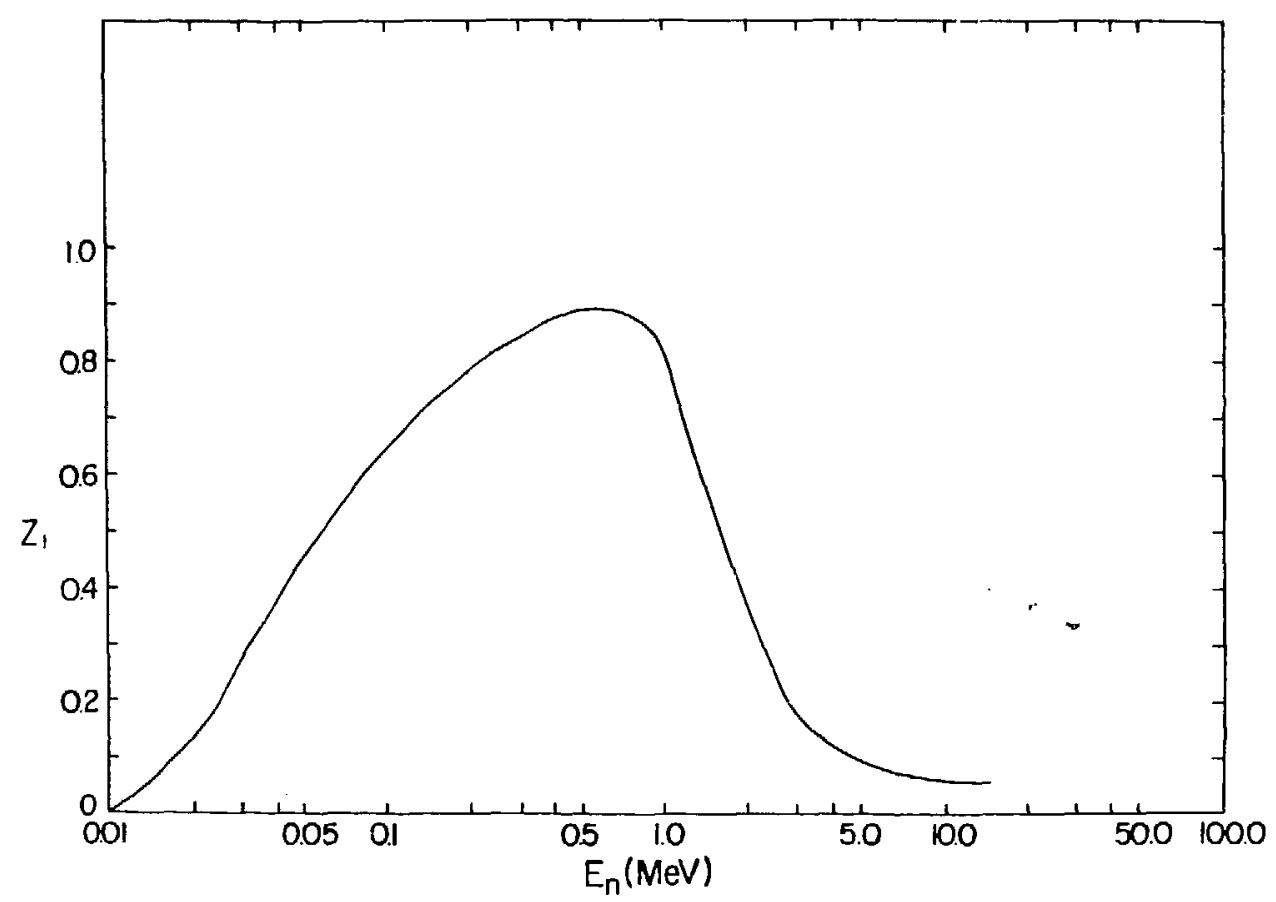

Fig. 17. Calculated ratio $\left(z_{1}\right)$ between the number of recoil protons in the region $>30-120 \mathrm{keV} / \mu$ to the total number of recoil protons in the region of $10-120 \mathrm{keV} / \mu$, for the $0.5 \mu$ chamber.

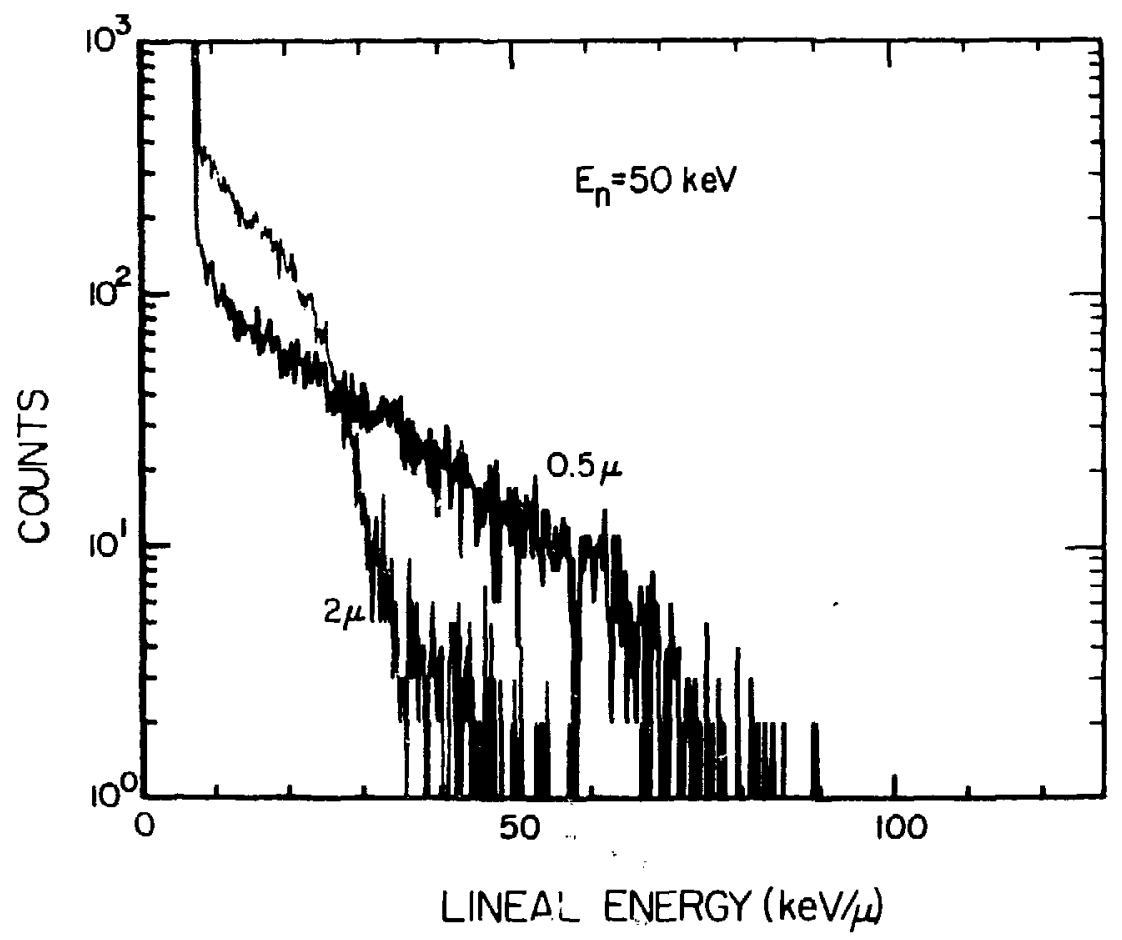

Fig. 18. Experimental energy deposition spectra as a function of lineal energy for $50 \mathrm{keV}$ incident neutrons and for the 0.5 and the $2 \mu$ chambers. Neutrons were generated in the ${ }^{7} \mathrm{Li}(\mathrm{p}, \mathrm{n}){ }^{7} \mathrm{Be}$ reaction. The chambers were positioned symmetrically about the beam 1 ine and thus received the same number of incident neutrons. 


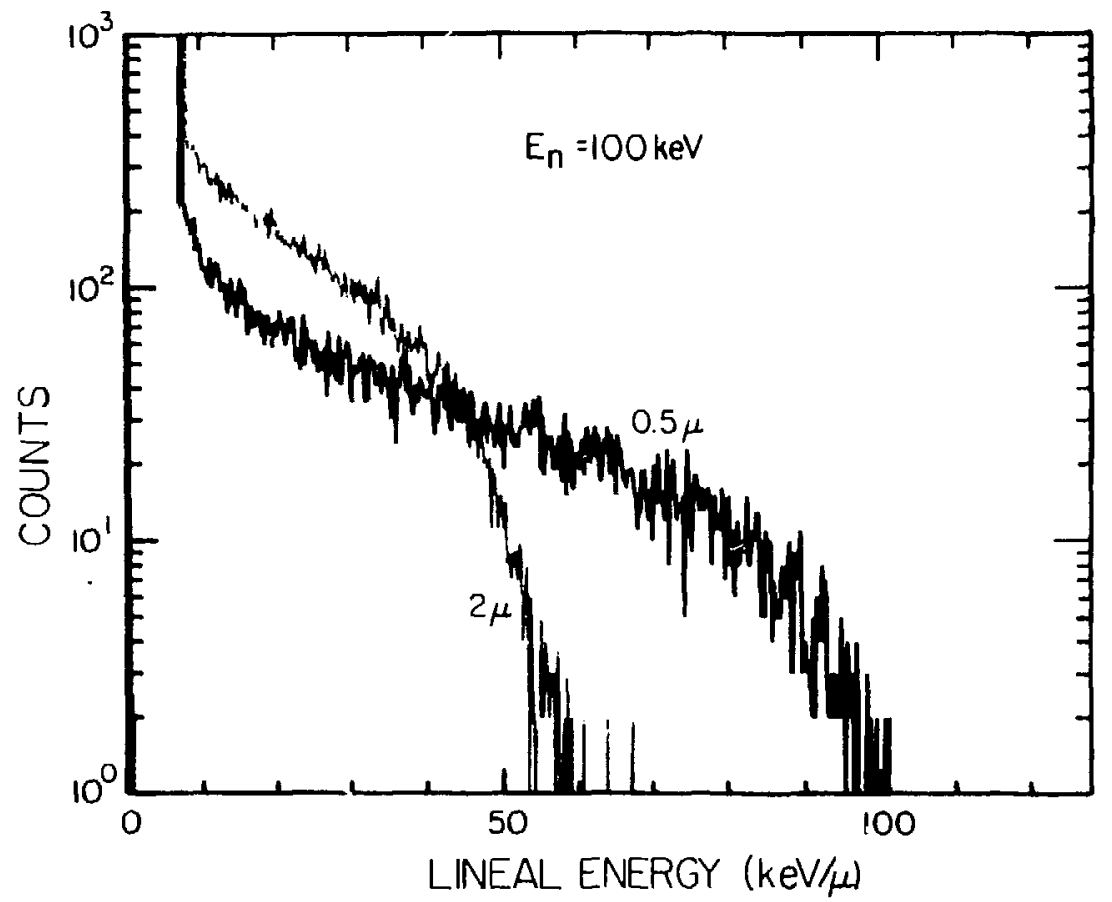

Fig. 19. Experimental energy deposition spectra as in Fig. 18 for $100 \mathrm{keV}$ incident neutrons.

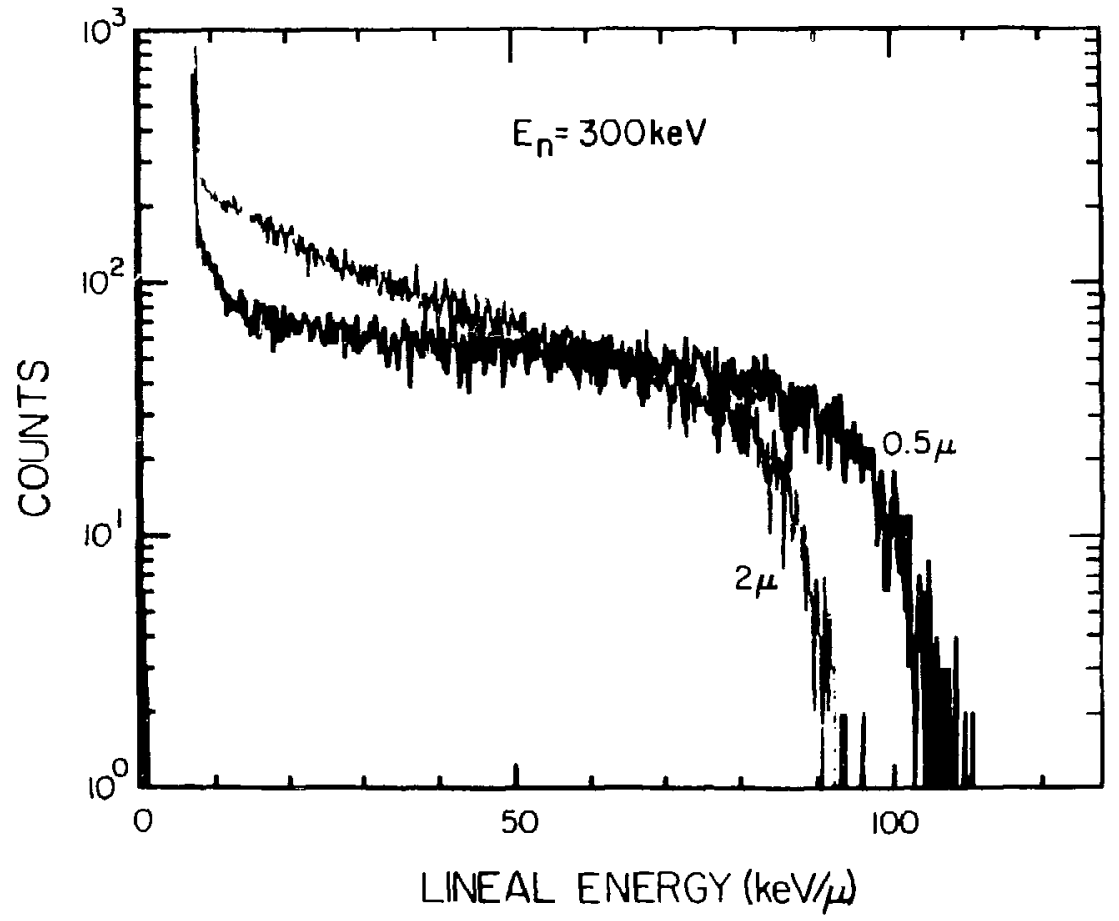

Fig. 20. Experimental energy deposition spectra as in Fig. 18 for $300 \mathrm{keV}$ incident neutrons. 


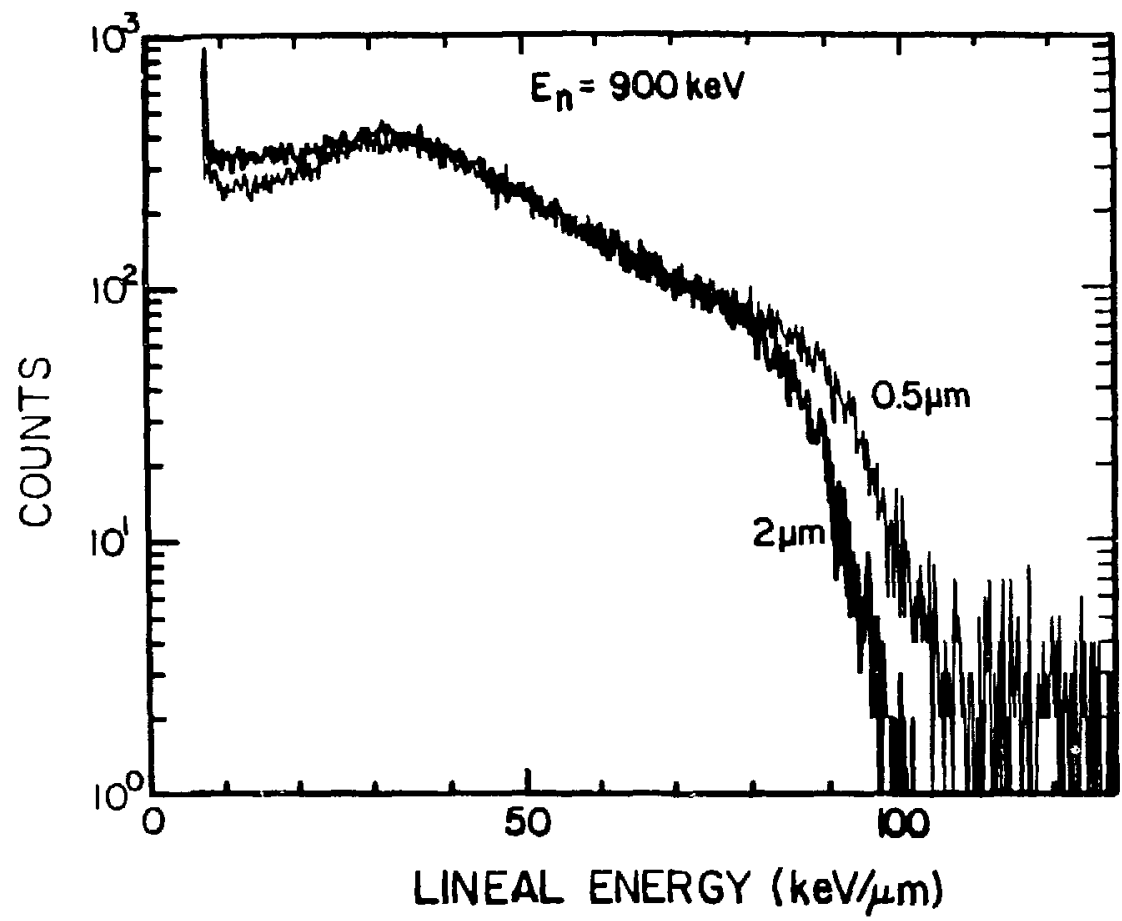

Fig. 21. Experimenta1 energy deposition snectra as in Fig. 18 for $900 \mathrm{keV}$ incident neutrons.

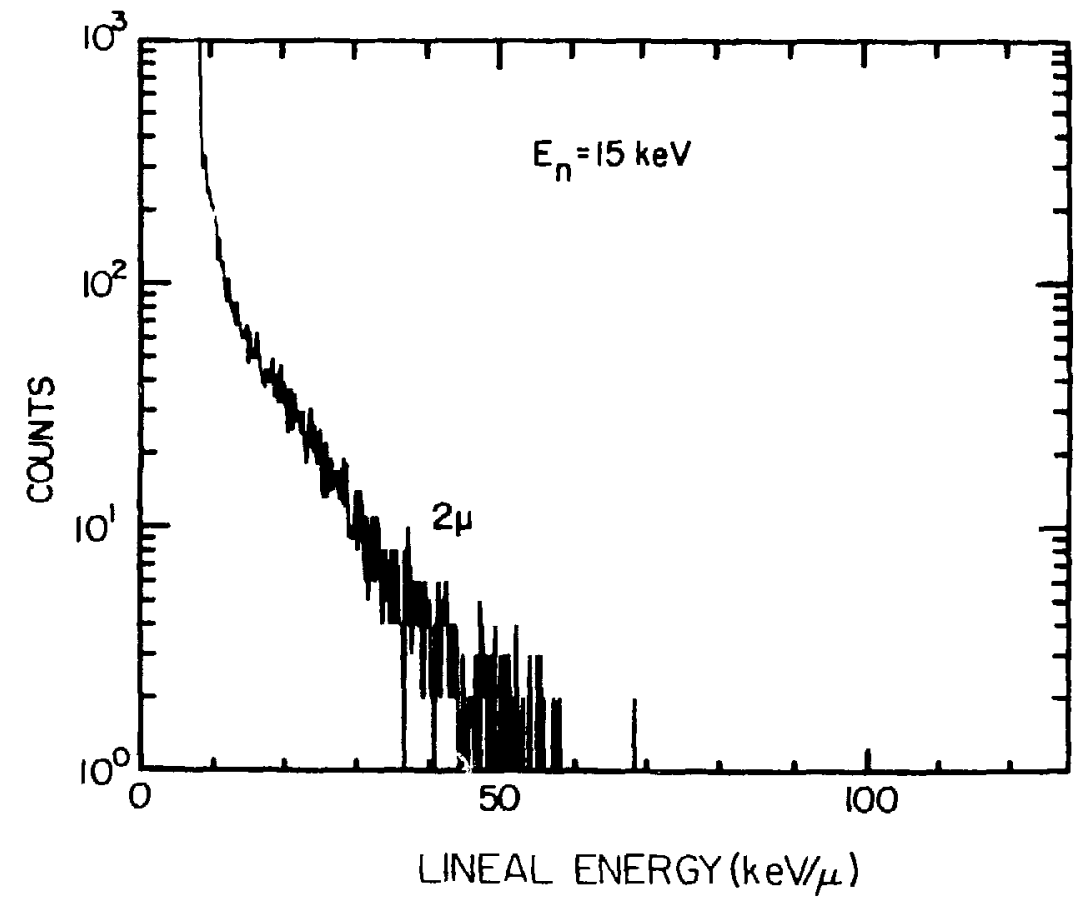

Fig. 22. Experimental energy deposition spectra in the $2 \mu$ chamber for incident neutron energy of $15 \mathrm{keV}$. 

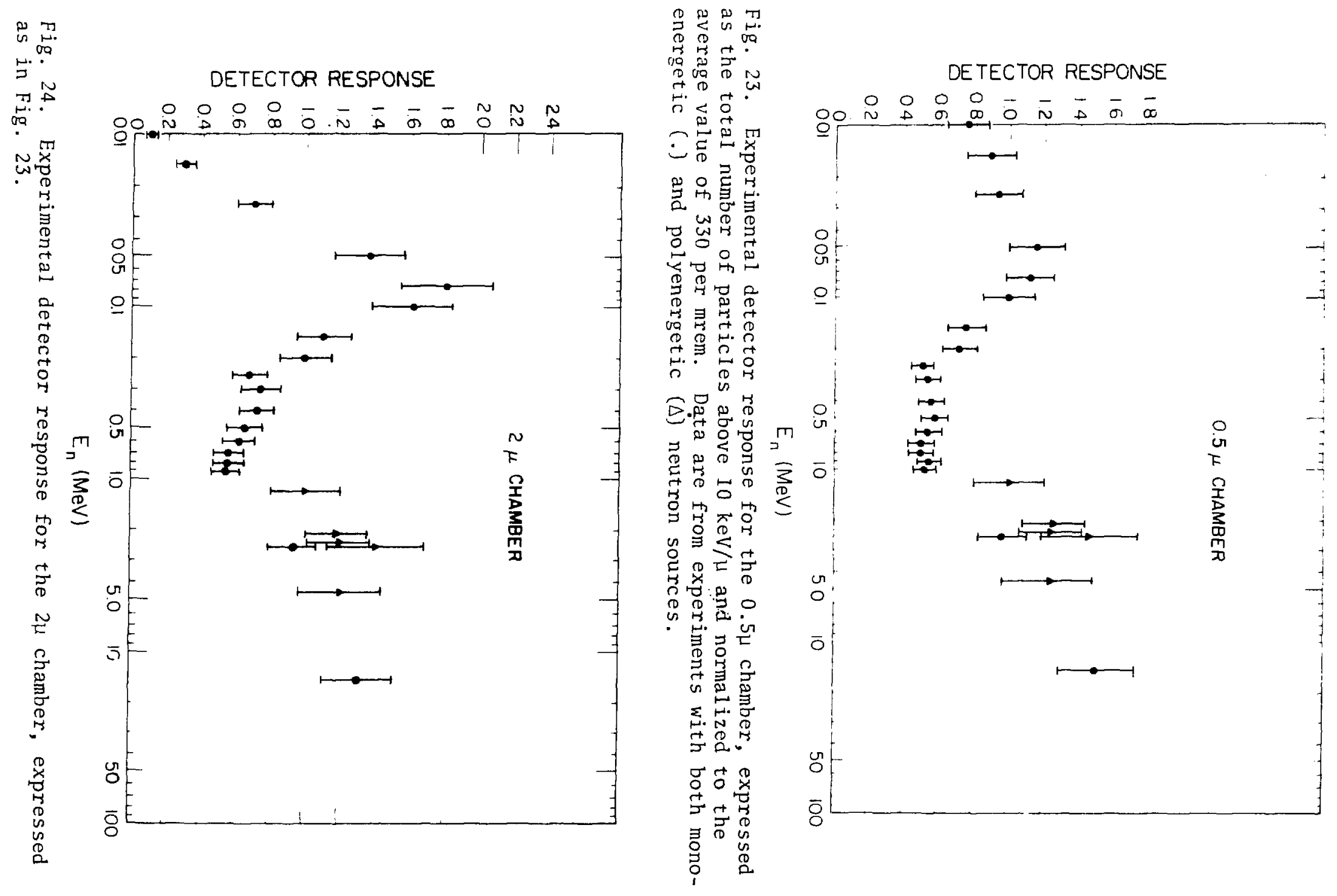


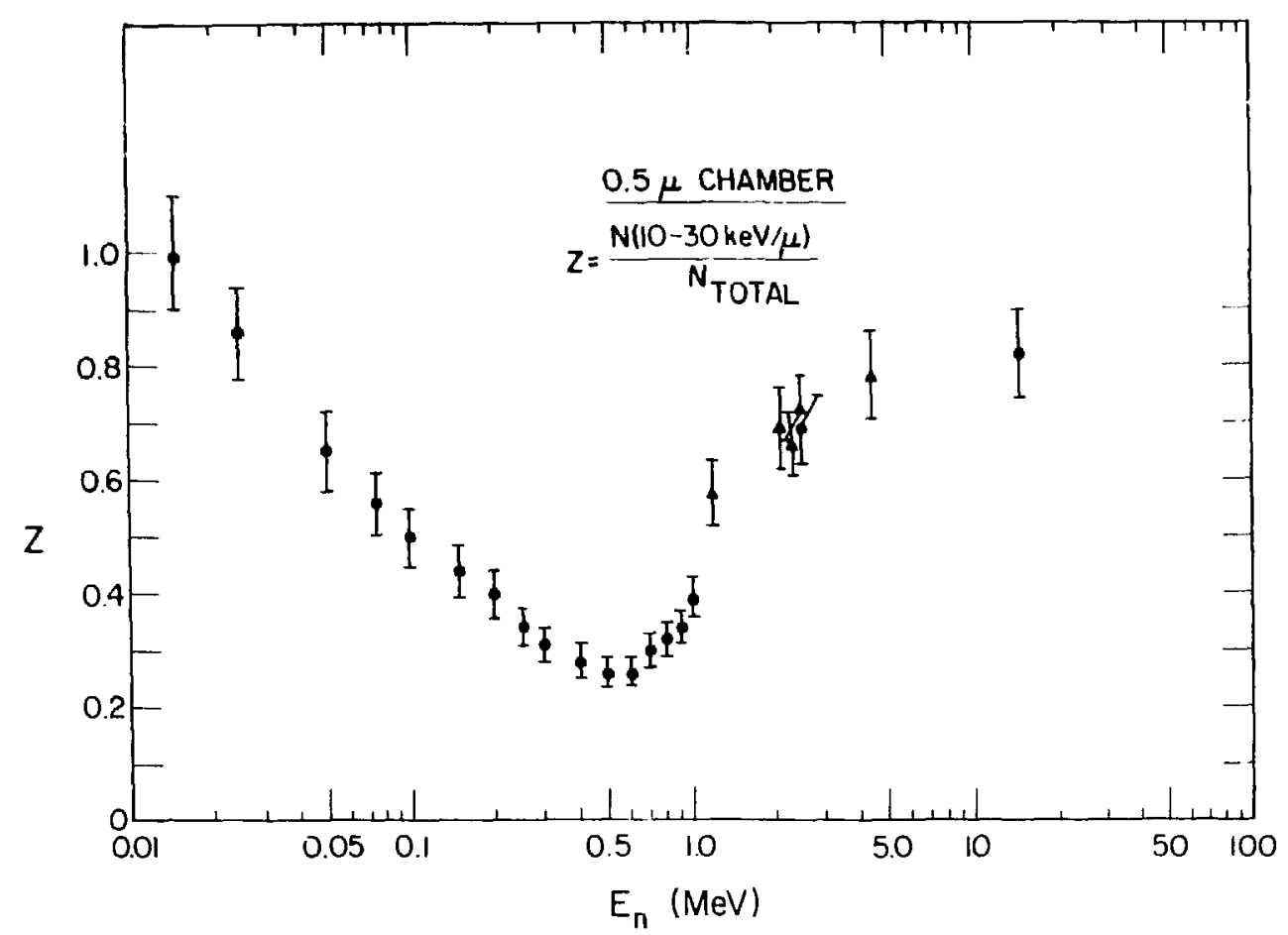

Fig. 25. Experimental ratio ( $Z$ ) between the number of recoil particles in the region of $(10-30) \mathrm{keV} / \mu$ and the total number of recoil particles in the region of $(10-120) \mathrm{keV} / \mu$, for the $0.5 \mu$ chamber. Symbols are as in Fig. 23.

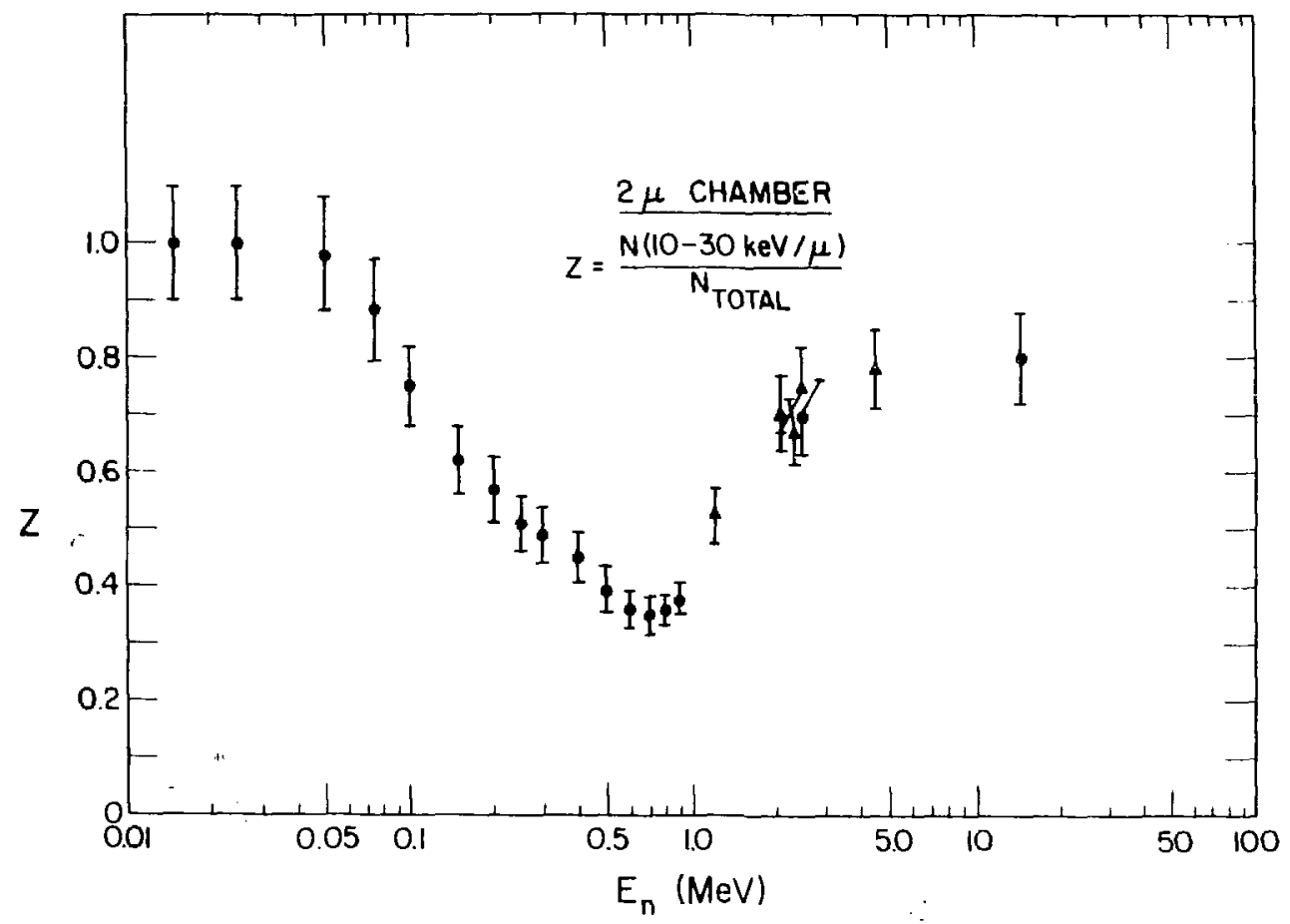

Fig. 26. Experimental ratio $(Z)$ between the number of recoil particles in the region of $(10-30) \mathrm{keV} / \mu$ and the total number of recoil particles in the region of $(10-120) \mathrm{keV} / \mu$ for the $2 \mu$ chamber. Symbols are as in Fig. 23. 


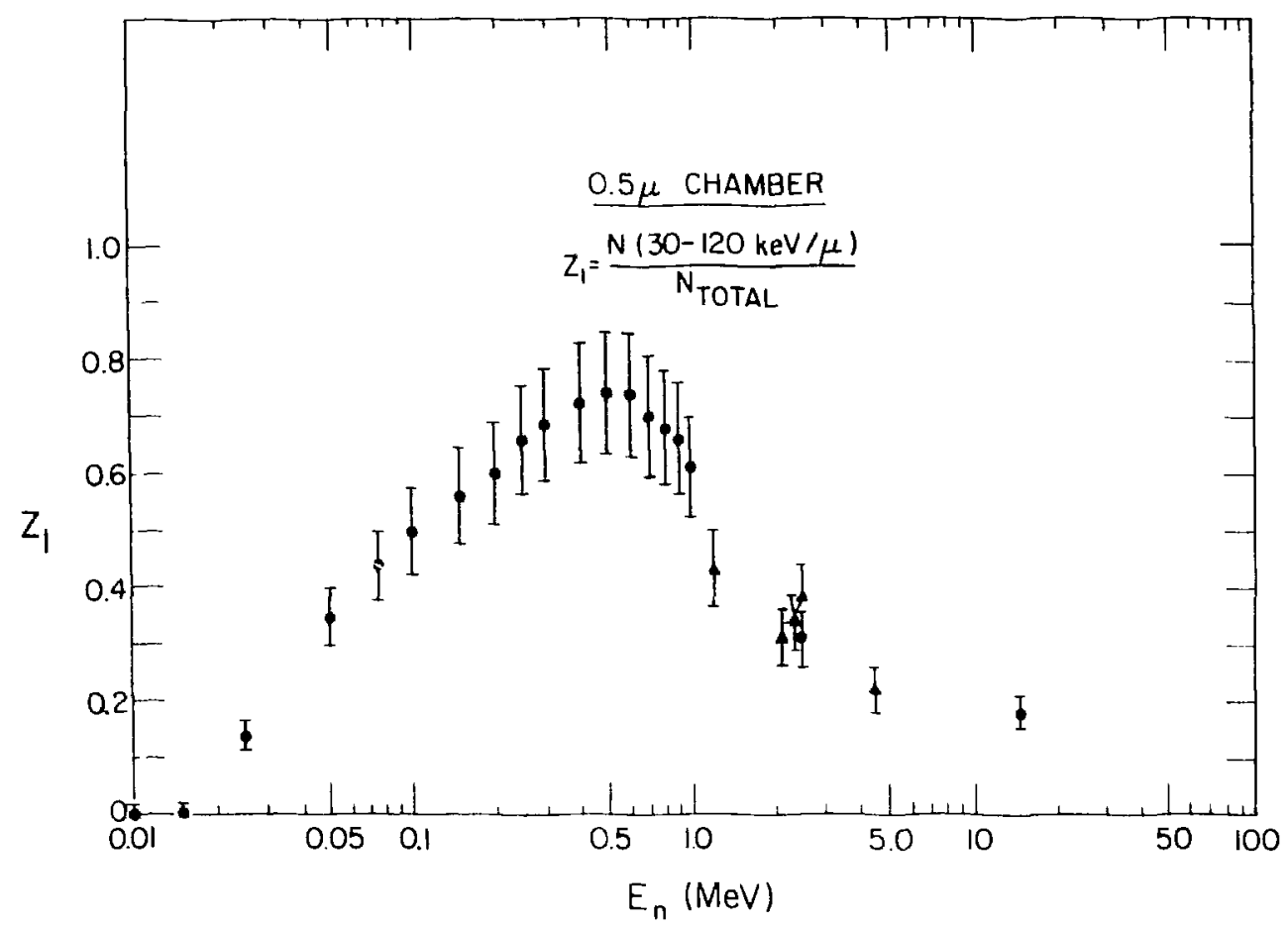

Fig. 27. Experimental ratio $\left(z_{1}\right)$ between the number of recoil protons in the region $(30-120) \mathrm{keV} / \mu$ to the total number of recoil particles in the region $(10-120) \mathrm{keV} / \mu$ for the $0.5 \mu$ chamber. Symbols are as in Fig. 23.

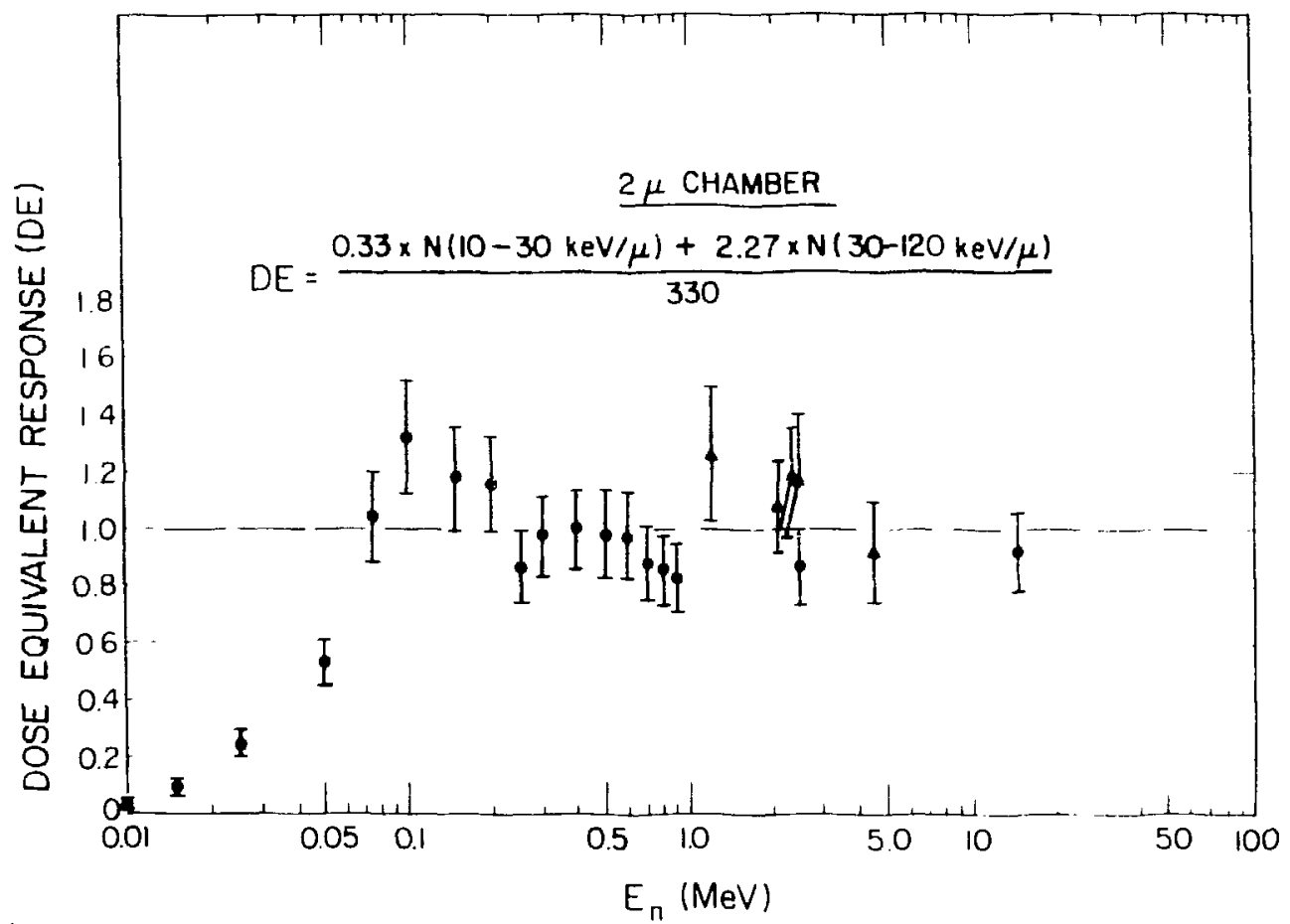

Fig. 28. The dose equivalent response (in mrem, given by Eq. 26) as a function of the incident neutron energy for the $0.5 \mu$ chamber. The quantities $N(10-30 \mathrm{keV} / \mu)$ and $N(30-120 \mathrm{keV} / \mu)$ are the experimental number of particles in the $(10-30) \mathrm{keV} / \mu$ and $(>30-120) \mathrm{keV} / \mu$ regions, respectively. Symbols are as in Fig. 23. 


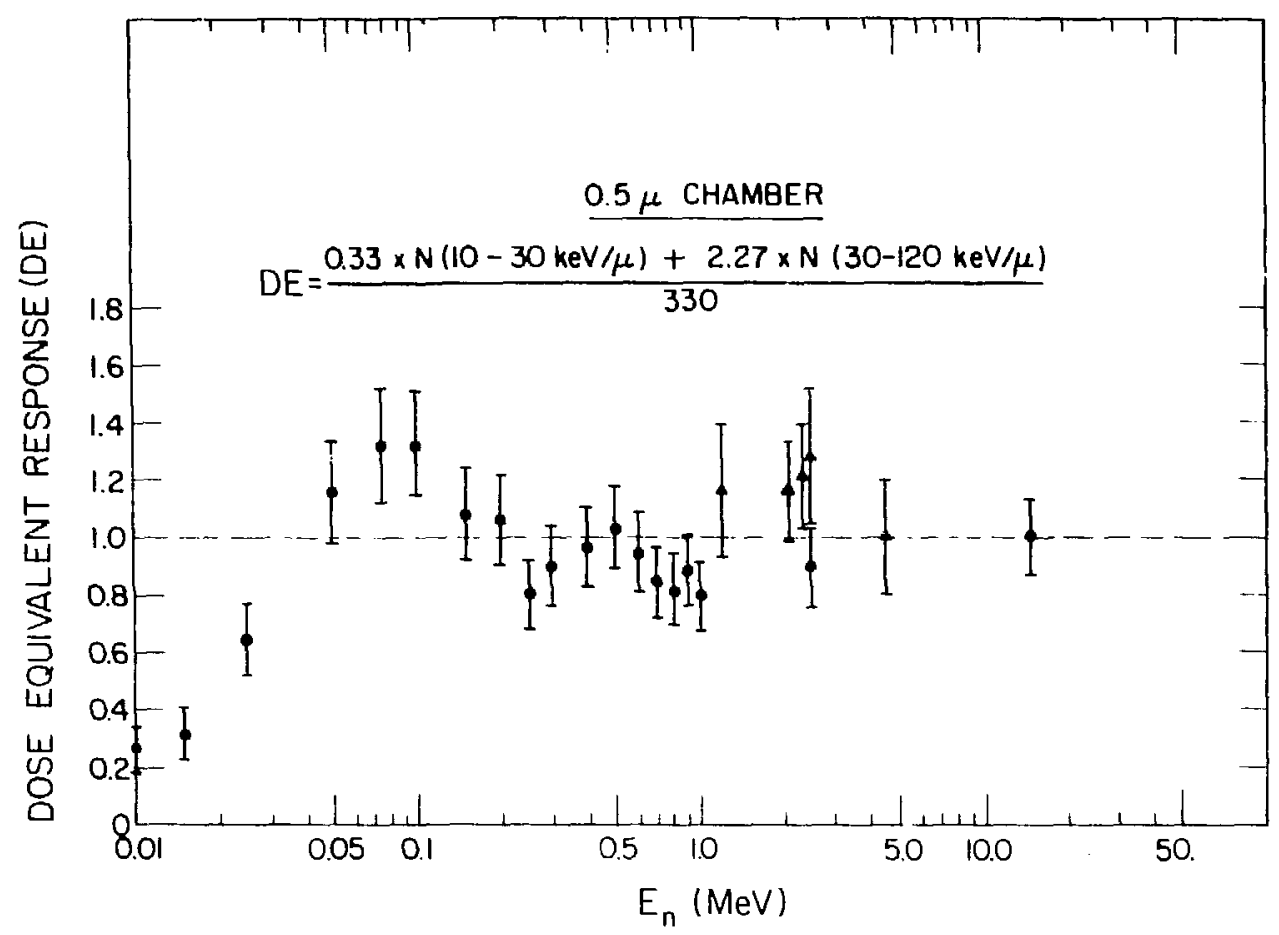

Fig. 29. The dose equivalent response as in Fig. 29 for the $2 \mu$ chamber. Symbols are as in Fig. 23. 